\title{
Fire Dynamics Simulation and Evacuation for a Large Shopping Center (Mall): Part I, Fire Simulation Scenarios
}

\author{
Khalid A. Albis", Muhammad N. Radhwi, Ahmed F. Abdel Gawad \\ Mechanical Engineering Department, College of Engineering \& Islamic Architecture, Umm Al-Qura University, Makkah, Saudi Arabia
}

Email address:

kalbis31@gmail.com (K. A. Albis),mnradhwi@uqu.edu.sa (M. N. Radhwi), afaroukg@yahoo.com (A. F. A. Gawad)

To cite this article:

Khalid A. Albis, Muhammad N. Radhwi, Ahmed F. Abdel Gawad. Fire Dynamics Simulation and Evacuation for a Large Shopping Center (Mall): Part I, Fire Simulation Scenarios. American Journal of Energy Engineering. Special Issue: Fire, Energy and Thermal Real-life Challenges. Vol. 3, No. 4-1, 2015, pp. 52-71. doi: 10.11648/j.ajee.s.2015030401.14

\begin{abstract}
Malls like any retailing centers face exposure for a host of risks including fire, which is no stranger to shopping malls. Fires in closed malls, patronized by lots of people, can cause many fatalities among panicked people running and pushing to get out of these burning places and great damage to the property itself. This computational study covers the possibilities of smoke propagation and evacuation due to hazardous fires in a large shopping center (mall) in Makkah, Saudi Arabia. The mall occupies 50,753 $\mathrm{m}^{2}$ and has two main floors. It contains 144 stores in the ground floor and 56 stores in the upper floor. It has five gates, one elevator, four escalators and five emergency exit stairs. The study is divided into two parts. Part I concerns four scenarios of fire simulation. Part II considers corresponding four scenarios of evacuation. The present results explain how fast the smoke may spread in such buildings and its mechanism to move from one floor to another. The smoke propagation/movement is highly affected by the architecture of the building and the type of activities inside it.
\end{abstract}

Keywords: Fire Dynamics Simulation, Smoke Propagation, Shopping Center (Mall)

\section{Introduction}

\subsection{Fire Dynamics Simulator}

Fire dynamics simulator $(F D S)$ is a computational fluid dynamics $(C F D)$ program of fire-driven fluid flow. The software solves numerically a large eddy simulation (LES) form of the Navier-Stokes equations appropriate for lowspeed, thermally-driven flow, with an emphasis on smoke and heat transport from fires. FDS is free software developed by the National Institute of Standards and Technology (NIST) of the United States Department of Commerce, in cooperation with VTT Technical Research Centre of Finland. Smokeview is the companion visualization program that can be used to display the output of FDS [1]. Throughout its development, $F D S$ has been aimed at solving practical fire problems in fire protection engineering, while at the same time providing a tool to study fundamental fire dynamics and combustion [1]. In the present investigation, PyroSim program [2] was used as interface software to construct the architecture of the investigated mall, and computational domain and mesh. It was also used for other programming aspects such as heat/smoke detectors, sprinklers, etc.

\subsection{Objectives of the Present Study}

This paper utilizes FDS to study the smoke propagation/movement in large shopping centers (malls). Usually, fires in closed malls that are attended daily by a big number of visitors can cause many fatalities among panicked people running and pushing to get out of the on-fire mall. Due to the large volume of malls and the complexity of their structure, it is difficult to predict the smoke movement in case of fire. Thus, evacuation plans cannot be set easily.

Therefore, the present research considers the smoke movement due to fire spots in different locations in a large shopping center (mall). This mall contains various activities such as clothing and fabric stores, boutiques, food markets, food court, entertainment facility, etc. Moreover, evacuation plans were proposed based on the predicted results of the smoke propagation to ensure safe and quick evacuation of the visitors as will appear in part II. In addition, $F D S$ was used to quantify the performance of smoke/fire detectors in terms of their response and the effect of smoke and temperature for large open space applications. 


\section{Literature Review}

\subsection{Fire Dynamic Simulation}

$F D S$ was employed to model a fire case in which three fire fighters were killed in order to estimate the concentration of carbon monoxide present in the dwelling, which was the immediate cause of death of two of the fire fighters [3]. FDS was used to optimize the location of smoke detectors in a large building in Hong Kong for early fire detection. A set of computer simulations was carried out to calculate smoke movement, smoke detection performance, and the overall protection in accordance with performance-based fire safety system design methodologies [4].

Hot smoke tests (HST) were performed according to Australian Standard AS 4391-1999 in several buildings to compare with the predictions of FDS. It was sated that data from hot smoke tests, if gathered cost effectively, can be a valuable resource for computer model verification [5]. A newly developed integrated system-BFIRESAS was introduced to analyze the overall fire safety behavior of large space structures under real-fire conditions. The results showed that the structural respond and behavior of large space buildings under fire conditions have the systemic nature of a coherent whole, rather than the local effect [6].

To investigate how different configurations in a retail premises affect the smoke spread and temperatures during a fire, eleven tests were performed in scale 1:2 of a large room with small ventilation openings near the floor. Also, the fire tests were simulated using $F D S$ to see how well $F D S$ simulates under-ventilated fires. It was stated that there are cases where the temperatures from the simulations and measurements correspond relatively well with each other and yet other cases when the simulated temperature is higher than the measured temperature. This depends on the simulation case, the position in the set-up and the time period compared [7]. FDS was implemented to investigate smoke detector spacing for spaces (corridors) with deep beam pockets and level ceilings concerning varying beam depth, beam spacing, corridor width, and ceiling height. A subset of the modeled corridor configurations was conducted with full-scale experiments to validate the findings of the modeling study [8].

$F D S$ was used to get the special characteristics of fire spread and smoke movement inside a supermarket as well as evacuation scenarios. The research provided some results for performance-based fire protection design in supermarket buildings [9]. In an attempt to investigate the accuracy of predictions of fire-induced flow into a compartment by $F D S$, finer grids and an inclusion of radiative heat in the combustion model were considered. Results revealed significant improvements to the prediction of mass flow rates for all the three positions of the fire source considered in the study [10].

A study on the fire dynamics within a large compartment with openings was carried out using FDS,v5. The study concerned a heat source placed within the basement that was ignited and the flames eventually reached the ceiling causing further ignition of the wood, continuing the spread of flame and heat [11]. Considering the characteristics of fire in the cabin of Civil Aviation, FDS and evacuation software Evac were utilized. An example of cabin fire was used to explain how to employ the software and apply the results to the practical evacuation and rescue of cabin fire [12].

Other studies concerned fire and smoke aspects in big multi-story buildings/structures can be found in [13-15].

\subsection{Examples of Worldwide Fire Cases in Shopping Malls}

In 2010, a fire completely destroyed the Garver Brothers Store, in Ohio, United States. Nineteen fire departments responded to the blaze, using so much water that they were forced to draw directly from the Tuscarawas River but they quickly saw that all their efforts were necessary simply to preserve neighboring buildings [16]. Thirteen children and six adults were killed due to sprinkler system's malfunction after a fire broke out in Doha mall blaze in the Qatari capital Doha in 2012. Firefighters were forced to break through roof to evacuate victims. Relative of one two-yearold victim said building did not appear to have fire alarms [17].

A fire accident occurred in a five-story marketplace in Kolkata, the capital city of West Bengal, India, in 2013. An estimated 19 people who were mostly laborers working in the market were killed in the accident. Initial reports indicated that the fire might have been initiated by a short circuit in the first floor of the market [18]. A stubborn fire lit up the night sky and sent debris and sparks flying high into the air as it destroyed a Route 9 mall; housing more than a dozen businesses. While it appeared to begin as a small fire, it spread rapidly as firefighters using aerial ladder and large hoses doused it from all angles, to no avail. The wood frame building assessed at $\$ 1,033,400$, had several rooflines and ceilings and no sprinkles [19].

A fire sparked by a short circuit at a shop quickly engulfed a three-story shopping center in the eastern Pakistani city of Lahore killing at least 13 people in 2014.The fire broke out at the Anrkali Basaar. The building, which mostly houses shops that sells watches and clocks, had no firefighting equipment and no emergency exits. People inside were forced to flee through a single door, and most of the victims suffocated to death [20]. Fire ripped through stores at Main Street mall in Sayreville, in New Jersey, USA, in 2015. The fire consumed several stores, including a nail salon where the fire is believed to have started. The fire burned through at least three stores. But no injuries were reported [21].

Five people died and up to 25 people were missed due to a fire at a shopping centre (Admiral Centre) in the Russian city of Kazan in 2015. The fire started in a first-floor cafe and more than 600 people were cleared from the building. Part of the centre collapsed and forty people were injured in the blaze. It was reported that the building hadn't been equipped with fire safety and smoke control systems [22]. 


\section{Governing Equations and Solution Procedure}

This section presents the governing equations of $F D S$ and an outline of the general solution procedure. The governing equations are presented as a set of partial differential equations, with appropriate simplifications and approximations. The numerical method essentially consists of a finite-difference approximation of the governing equations and a procedure for updating these equations in time. This section is based on [23].

\subsection{Governing Equations}

This section introduces the basic conservation equations for mass, momentum and energy for a Newtonian fluid. Note that this is a set of partial differential equations consisting of six equations for six unknowns, all functions of three spatial dimensions and time: density $\rho$, three components of velocity $u=[u, v, w] T$, temperature $T$, and pressure $p$.

\subsubsection{Mass and Species Transport}

Mass conservation can be expressed either in terms of the density, $\rho$,

$$
\frac{\partial \rho}{\partial \mathrm{t}}+\nabla \cdot \rho \mathrm{u}=\dot{m}_{b}^{m}
$$

$$
\tau_{i j}=\mu\left(2 S_{i j}-\frac{2}{3} \delta_{i j}(\nabla \cdot \mathrm{u}) ; \delta_{i j}=\left\{\begin{array}{ll}
1 & i=j \\
0 & i \neq j
\end{array} ; S_{i j}=\frac{1}{2}\left(\frac{\partial u i}{\partial x j}+\frac{\partial u j}{\partial x i}\right) \mathrm{i}, \mathrm{j}=1,2,3\right.\right.
$$

The term $S_{i j}$ is the symmetric rate-of-strain tensor, written using conventional tensor notation. The symbol $\mu$ is the dynamic viscosity of the fluid. The overall computation can either be treated as a Direct Numerical Simulation (DNS), in which the dissipative terms are computed directly, or as a Large Eddy Simulation (LES), in which the large-scale eddies are computed directly and the subgrid-scale dissipative processes are modeled. The numerical algorithm is designed so that $L E S$ becomes $D N S$ as the grid is refined. Most applications of $F D S$ are $L E S$. For example, in simulating the flow of smoke through a large, multi-room enclosure, it is not possible to resolve the combustion and transport processes directly. However, for small-scale combustion experiments, it is possible to compute the transport and combustion processes directly. For the purpose of outlining the solution procedure below, it is sufficient to consider the momentum equation written as:

$$
\frac{\partial \rho}{\partial \mathrm{t}}+\mathrm{F}+\nabla \mathrm{H}=0
$$

and the pressure equation as

$$
\nabla^{2} \mathrm{H}=-\frac{\partial}{\partial t}(\nabla \cdot \mathrm{u})-\nabla \cdot \mathrm{F}
$$

which is obtained by taking the divergence of the momentum equation.

\subsubsection{Energy Transport}

The energy conservation equation is written in terms of the or in terms of the individual gaseous species, $Y \alpha$ :

$$
\frac{\partial}{\partial \mathrm{t}}(\rho \mathrm{Y} \alpha)+\nabla \cdot \rho \mathrm{Y} \alpha \mathrm{u}=\nabla \cdot \rho \mathrm{D} \alpha \nabla \mathrm{Y} \alpha+\dot{m}_{\alpha}^{m}+\dot{m}_{b, \alpha}^{m}
$$

Here, $\dot{m}_{b}^{m}=\sum \alpha \dot{m}_{b, \alpha}^{m}$ is the production rate of species by evaporating droplets or particles. Summing these equations over all species yields the original mass conservation equation because $\sum Y \alpha=1$ and $\sum \dot{m}_{\alpha}^{m}=0$ and $\sum \dot{m}_{b, \alpha}^{m}=\dot{m}_{b}^{m}$, by definition, and because it is assumed that $\sum \rho D \alpha \nabla Y \alpha=0$. This last assertion is not true, in general. However, transport equations are solved for total mass and all but one of the species, implying that the diffusion coefficient of the implicit species is chosen so that the sum of all the diffusive fluxes is zero.

\subsubsection{Momentum Transport}

The momentum equation in conservative form is written as:

$$
\frac{\partial}{\partial \mathrm{t}}(\rho \mathrm{u})+\nabla \cdot \rho \mathrm{uu}+\nabla \mathrm{p}=\rho \mathrm{g}+f_{b}+\nabla \cdot \tau_{i j}
$$

The term $u u$ is a diadic tensor. In matrix notation, with $u=[u, v, w] T$, the diadic is given by the tensor product of the vectors $u$ and $u T$. The term $\nabla \cdot \rho u u$ is thus a vector formed by applying the vector operator $\nabla=(\partial \partial x, \partial \partial y, \partial \partial z)$ to the tensor. The force term $f_{b}$ in the momentum equation represents external forces such as the drag exerted by liquid droplets. The stress tensor $\tau_{i j}$ is defined as:

sensible enthalpy, $h_{s}$ :

$$
\frac{\partial}{\partial \mathrm{t}}(\rho \mathrm{hs})+\nabla \cdot \rho h_{s} \mathrm{u}=\frac{D p}{D t}+\dot{q}^{\prime \prime \prime}-\dot{q}_{b}^{\prime \prime \prime}-\nabla \cdot \dot{q}^{\prime \prime}+\varepsilon
$$

The sensible enthalpy is a function of the temperature:

$$
h_{s}=\sum_{\propto} Y \alpha h_{s}, \alpha ; h_{s}, \alpha(T)=\int_{T_{o}}^{T} c_{p}, \alpha\left(\mathrm{T}^{\prime}\right) \mathrm{dT}^{\prime}
$$

Note the use of the material derivative, $D() / D t=\partial() / \partial t$ $+u \cdot \nabla()$. The term $\dot{q}^{\prime \prime \prime}$ is the heat release rate per unit volume from a chemical reaction. The term $\dot{q}_{b}^{\prime \prime \prime}$ is the energy transferred to the evaporating droplets. The term $\dot{q}^{\prime \prime}$ represents the conductive and radiative heat fluxes:

$$
\dot{q}^{\prime \prime}=-\mathrm{k} \nabla \mathrm{T}-\sum_{\alpha} h_{s}, \alpha \rho \mathrm{D} \alpha \nabla \mathrm{Y} \alpha+\dot{q}_{r}^{\prime \prime}
$$

Where, $k$ is the thermal conductivity.

\subsubsection{Equation of State}

$$
\mathrm{p}=\frac{\rho R T}{\bar{W}}
$$

An approximate form of the Navier-Stokes equations appropriate for low Mach number applications is used in the model. The approximation involves the filtering out of acoustic waves while allowing for large variations in temperature and density. This gives the equations an elliptic character, consistent with low speed, thermal convective processes. In practice, this means that the spatially resolved pressure, $p(x, y, z)$, is replaced by an "average" or "background" 
pressure, $p_{m}(z, t)$, that is only a function of time and height above the ground.

$$
\bar{P} \mathrm{~m}(\mathrm{z}, \mathrm{t})=\rho \mathrm{TR} \sum_{\alpha} Y \alpha / W \alpha
$$

Taking the material derivative of the background pressure and substituting the result into the energy conservation equation yields an expression for the velocity divergence, $\mathrm{V} \dot{u}$ that is an important term in the numerical algorithm because it effectively eliminates the need to solve a transport equation for the specific enthalpy. The source terms from the energy conservation equation are incorporated into the divergence, which appears in the mass transport equations. The temperature is found from the density and background pressure via the equation of state.

\subsection{Solution Procedure}

FDS uses a second-order accurate finite-difference approximation to the governing equations on a series of connected recti-linear meshes. The flow variables are updated in time using an explicit second-order Runge-Kutta scheme. This section describes how this algorithm is used to advance in time the density, species mass fractions, velocity components, and background and perturbation pressure. Let $\rho^{\mathrm{n}}, Y_{\alpha}^{\mathrm{n}}, u^{\mathrm{n}}, \bar{p}_{\mathrm{m}}^{\mathrm{n}}$ and $H^{n}$ denote these variables at the $n^{\text {th }}$ time step.

1. Compute the "patch-average" velocity field $\bar{u}^{\mathrm{n}}$.

2. Estimate $\rho, Y \alpha$, and $\bar{P} \mathrm{~m}$ at the next time step with an explicit Euler step. For example, the density is estimated by

$$
\frac{\rho *-\rho n}{\delta t}+\nabla \cdot \rho^{n} \bar{u}^{n}=0
$$

3. Exchange values of $\rho^{*}$ and $Y_{\alpha}^{*}$ at mesh boundaries.

4. Apply boundary conditions for $\rho^{*}$ and $Y_{\alpha}^{*}$.

5. Compute the divergence, $\nabla \cdot \bar{u}^{*}$, using the estimated thermodynamic quantities. Note that at this stage, the velocity field has not been estimated at the next time step, only its divergence.

6. Solve the Poisson equation for the pressure fluctuation with a direct solver on each individual mesh:

$$
\nabla^{2} H^{n}=-\left[\frac{\nabla \cdot u^{*}-\nabla \cdot \bar{u}^{n}}{\delta t}\right]-\nabla \cdot \bar{F}^{n}
$$

Note that the vector $\bar{F}^{n}=\mathrm{F}\left(\rho^{\mathrm{n}}, \bar{u}^{\mathrm{n}}\right)$ is computed using patch-averaged velocities and that the divergence of the patch-averaged field is computed explicitly.

7. Estimate the velocity at the next time step

$$
\frac{u^{*}-\bar{u}^{n}}{\delta t}+\bar{F}^{n}+\nabla H^{n}=0
$$

Note that the divergence of the estimated velocity field is identically equal to the estimated divergence, $\nabla \cdot u^{*}$, that was derived from the estimated thermodynamic quantities.

8. Check the time step at this point to ensure that

$$
\delta \mathrm{t} \max \left(\frac{|u|}{\delta x}, \frac{|v|}{\delta y}, \frac{|w|}{\delta z}\right)<1 ; 2 \delta \operatorname{tv}\left(\frac{1}{\delta x^{2}}, \frac{1}{\delta y^{2}}, \frac{1}{\delta z^{2}}\right)<1
$$

If the time step is too large, it is reduced so that it satisfies both constraints and the procedure returns to the beginning of the time step. If the time step satisfies the stability criteria, the procedure continues to the corrector step.

This concludes the "Predictor" stage of the time step. At this point, values of $H^{n}$ and the components of $u^{*}$ are exchanged at mesh boundaries as follows:

1. Compute the "patch-average" velocity field $\bar{u}^{*}$.

2. Apply the second part of the Runge-Kutta update to the mass variables. For example, the density is corrected as

$$
\frac{\rho^{n+1}-\frac{1}{2}\left(\rho^{n}+\rho^{*}\right)}{\delta t / 2}+\nabla \cdot \rho^{*} \bar{u}^{*}=0
$$

3. Exchange values of $\rho^{n}$ and $Y_{\alpha}^{\mathrm{n}}$ at mesh boundaries.

4. Apply boundary conditions for $\rho^{\mathrm{n}}$ and $Y_{\alpha}^{\mathrm{n}}$.

5. Compute the divergence $\nabla \cdot u^{n+1}$ from the corrected thermodynamic quantities. Note again that the velocity field has not been corrected at the point.

6. Compute the pressure fluctuation using estimated quantities

$$
\nabla^{2} H^{*}=-\frac{\nabla \cdot u^{n+1}-\frac{1}{2}\left(\nabla \cdot \bar{u}^{*}+\nabla \cdot \bar{u}^{n}\right)}{\delta t / 2}-\nabla \cdot \bar{F}^{*}
$$

7. Update the velocity via the second part of the RungeKutta scheme

$$
\frac{u^{n+1}-\frac{1}{2}\left(\bar{u}^{*}+\bar{u}^{n}\right)}{\delta t / 2}+\bar{F}^{*}+\nabla H^{*}=0
$$

Note again that the divergence of the corrected velocity field is identically equal to the divergence that was computed earlier.

8. At the conclusion of the time step, values of $H^{*}$ and the components of $u^{n+1}$ are exchanged at mesh boundaries.

\subsection{Spatial Discretization}

Spatial derivatives in the governing equations are written as second-order accurate finite-differences on a rectilinear grid. The overall domain is a rectangular box that is divided into rectangular grid cells. Each cell is assigned indices $i, j$ and $\mathrm{k}$ representing the position of the cell in the $\mathrm{x}, \mathrm{y}$ and $\mathrm{z}$ directions, respectively. Scalar quantities are assigned in the center of each grid cell; thus, $\rho_{i j k}^{n}$ is the density at the nth time step in the center of the cell whose indices are $\mathrm{i}, \mathrm{j}$ and $\mathrm{k}$. Vector quantities like velocity are assigned at their appropriate cell faces. For example, $u_{i j k}^{n}$ is the x-component of velocity at the positive-oriented face of the ijkth cell; $u_{i-1, j k}^{n}$ is defined at the negative-oriented face of the same cell.

\section{Present Model (Mall) and Computational Aspects}

\subsection{Description of the Present Model (Mall)}

The mall is actually a big shopping center that provides a complete and comprehensive shopping and recreation for all family members in Makkah city, Saudi Arabia, Fig. 1. The mall occupies $50,753 \mathrm{~m}^{2}$ and has two main floors. It contains 
144 stores in the ground floor and 56 stores in the upper floor. It has five main gates, one elevator, four escalators, and five emergency exit stairs, Fig. 2. Most of the mall's stores are for clothing and fabric.

The ground floor has five main entrances and three main corridors that are perpendicular to other three main corridors and includes mainly stores. The upper floor consists of stores as well; in addition to recreation facilities and a food court with five emergency stairs. The building is surrounded by parking lots especially in the two directions of the entrances; front and back.

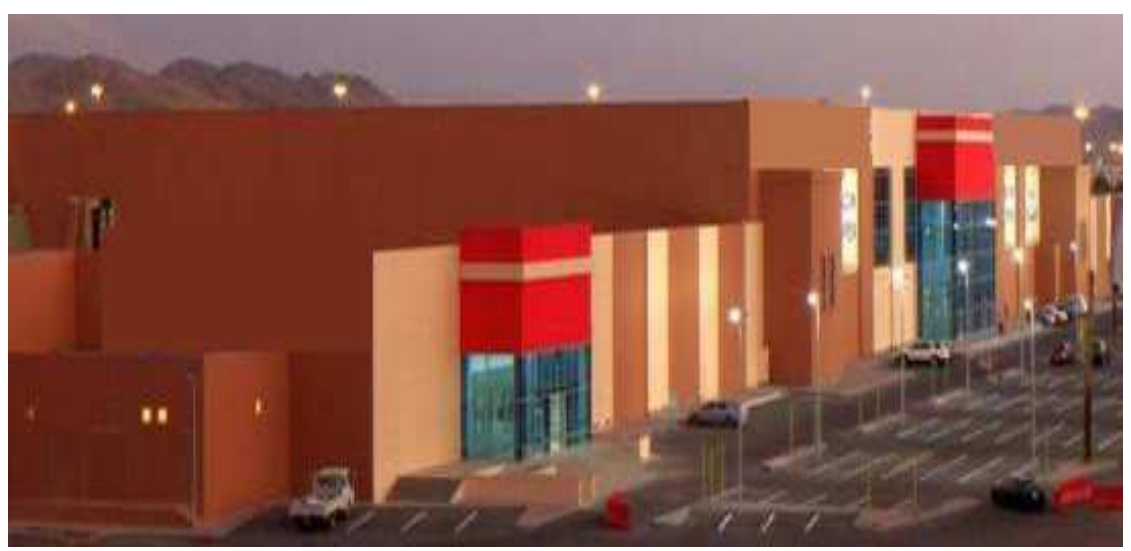

Figure 1. A picture of the front view of the mall.

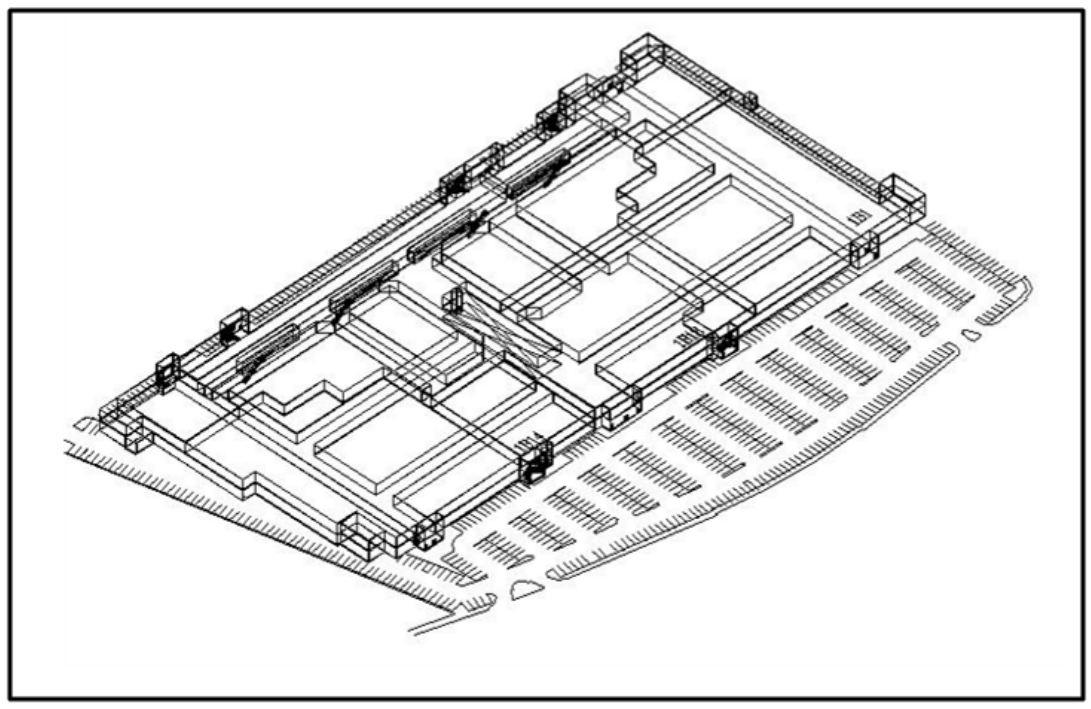

Figure 2. Three-dimensional drawing of the Mall.

\subsection{Computational Grid (Mesh)}

Usually, the computational grid of FDS is formed of uniform elements in the form of cuboids or cubes in the three dimensions of the building. The grid covers the whole space of the building. In the present study, cubic elements $\left(0.2 \times 0.2 \times 0.2 \mathrm{~m}^{3}\right)$ were used. The grid dimensions along the front of the mall ( $x$-direction), along the width of the mall (ydirection), and along the height of the mall (z-direction) are $340 \mathrm{~m}, 179 \mathrm{~m}$, and $20 \mathrm{~m}$, respectively.

Figure 3(a) shows an overall view of the grid of the whole mall. The grid elements in two planes along the front of the mall ( $x$-direction), and along the width of the mall (ydirection) are shown in Fig. 3(b). Figure 3(c) shows a zoomed $2 D$ view of the grid elements that take a square

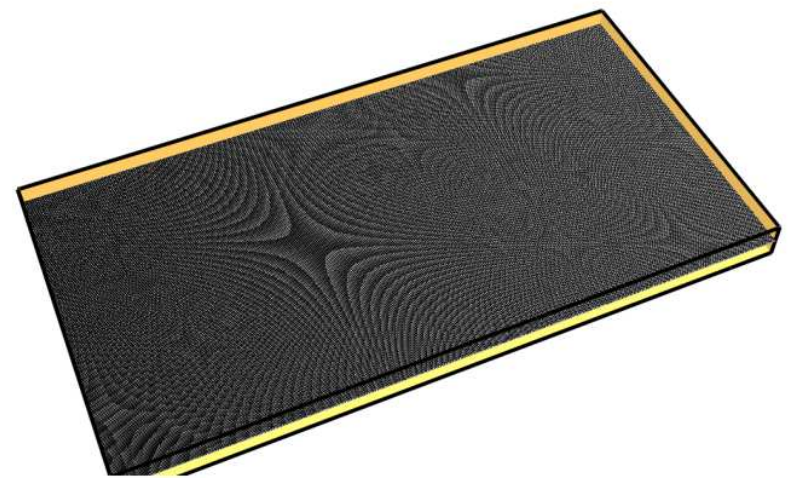

Figure 3(a). verall view of the grid of the whole mall. shape. 


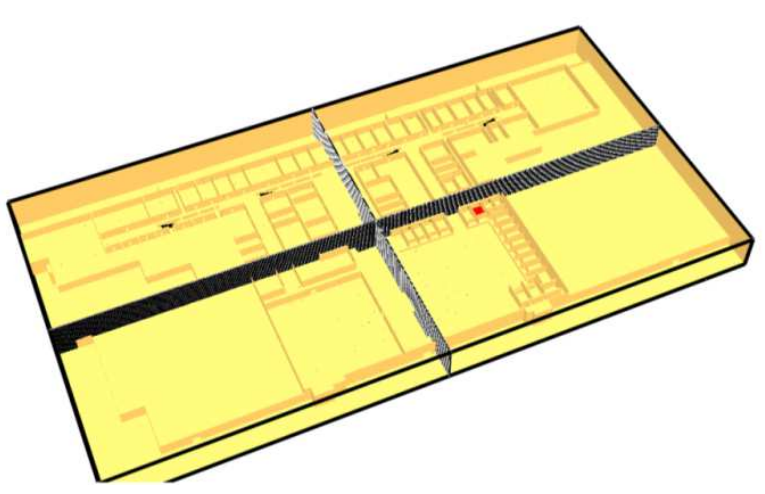

Figure 3(b). rid elements in two planes along the front of the mall (xdirection), and along the width of the mall (y-direction).

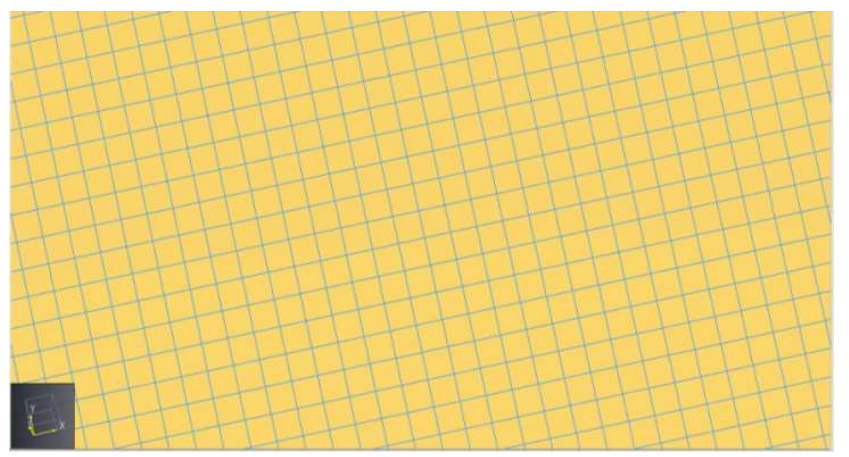

Figure 3(c). Zoomed $2 D$ view of the grid elements.

Figure 3. Present computational grid.

\subsection{Sprinklers and Heat/Smoke Detectors}

Sprinkler is a device that spreads water on the fire location according to fire signal to suppress fire at its early stages [2427]. Heat detector is a fire detector that detects either abnormally high temperature or rate of temperature rise or both. Smoke detector is a device that detects visible or invisible particles of combustion [28].

To simulate the actual situation of the mall, grids of sprinklers and heat/smoke detectors were constructed. The sprinklers and detectors were distributed in both floors according to their actual distribution in the mall.

Thus, the total number of sprinklers, smoke detectors, and heat detectors are 7848,844 , and 20 , respectively in the whole mall.

Figure 4(a) shows a close view of the distribution of sprinklers (Blue), smoke detectors (Green), and heat detectors (Red). As heat detectors sense high temperature, they are placed in the kitchens of the food court. Figure 4(b) shows a plane of the ground floor that illustrates the sprinkles, and smoke detectors that cover the whole area of the ground floor. Figure 4(c) shows a plane of the upper floor that illustrates the sprinkles, and smoke and heat detectors that cover the whole area of the upper floor. As can be seen in Fig. 4(c), some spaces of the upper floor, to the far right and left, are still empty without stores. It is clear from Figs. 4(b) and 4(c) that huge numbers of sprinklers and smoke detectors were modeled in the present work, which needed big effort and consumed a lot of time.

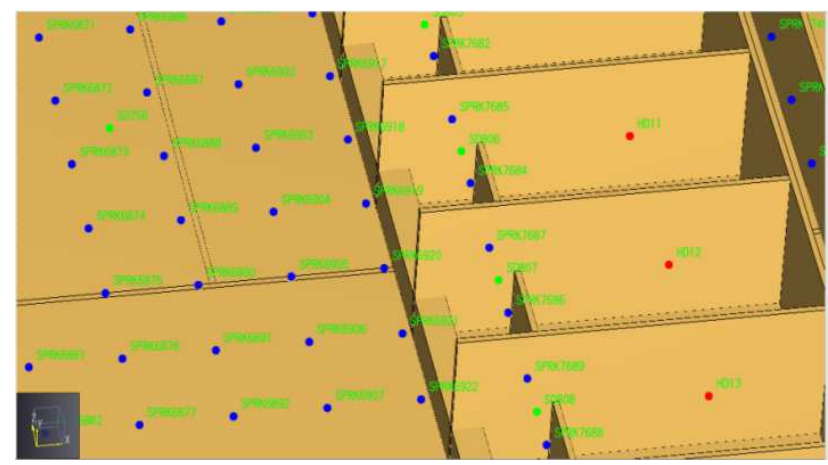

Figure 4(a). lose view of the distribution of sprinklers (Blue), smoke detectors (Green), and heat detectors (Red).

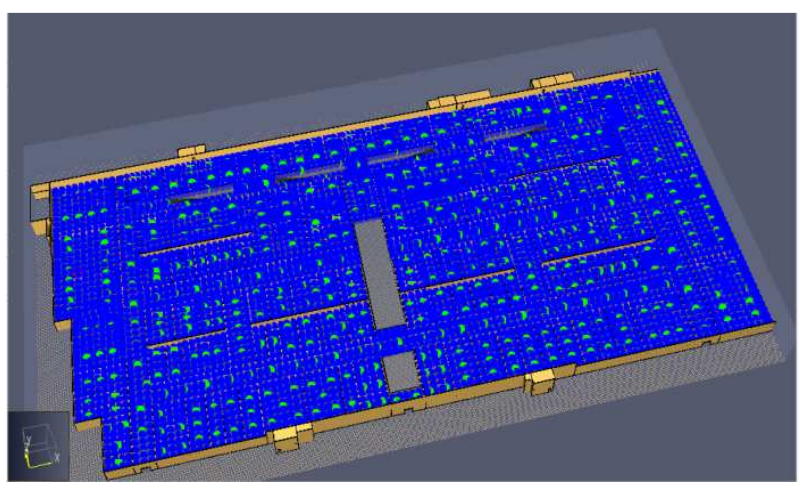

Figure 4(b). lane of the ground floor with sprinkles (Blue), and smoke detectors (Green) for the ground floor.

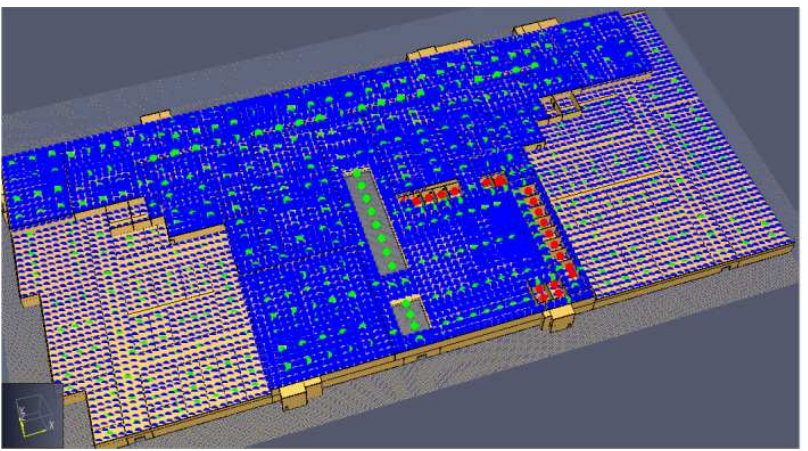

Figure 4(c). lane of the upper floor with sprinkles (Blue),smoke detectors (Green), and heat detectors (Red) for the upper floor.

Figure 4. istributions of sprinklers, and smoke and heat detectors.

\section{Results and Discussions}

\subsection{Case Studies}

To investigate the different possibilities of smoke propagation/movement in the mall, four case studies were considered. Two of these case studies concerned the fire ignition in two locations in the upper floor as occupants' evacuation would be more difficult. Two other case studies considered fire ignition in the ground floor. Based on these four fire simulations, four corresponding evacuation simulations were carried out, Part II.

In all cases, the Heat Release Rate per Unit Area (HRRPUA) was fixed at $250 \mathrm{~kW} / \mathrm{m}^{2}$ [29]. More estimates of HRRPUA for different applications can also be found in 
[30,31]. The computations of fire simulation continued to 900 seconds (15 minutes) except for case (4), which was terminated at 420 seconds ( 7 minutes) as this time was sufficient to design the corresponding evacuation plan. The ambient temperature of the mall was kept at $20^{\circ} \mathrm{C}$. It should be noted that pressure fans of the emergency exits were not considered in the present study. As will be seen in all fire simulation cases, sprinkles in the fire region worked successfully. The sprinkles were not able to overcome the fire because the HRRPUA of the fire was set as constant. However, they slightly lowered the temperature in the fire region.

\subsection{Fire Simulation Cases}

\subsubsection{Case Study (1)}

The first case study concerned a fire ignition at one of the kitchens of the food court in the upper floor. To facilitate the following of the smoke propagation and movement with time, the important parts of the upper floor (main stores, corridors, emergency exits, etc.) are notified and numbered as can be seen in Fig. 5. The fire was set at kitchen no. 7.

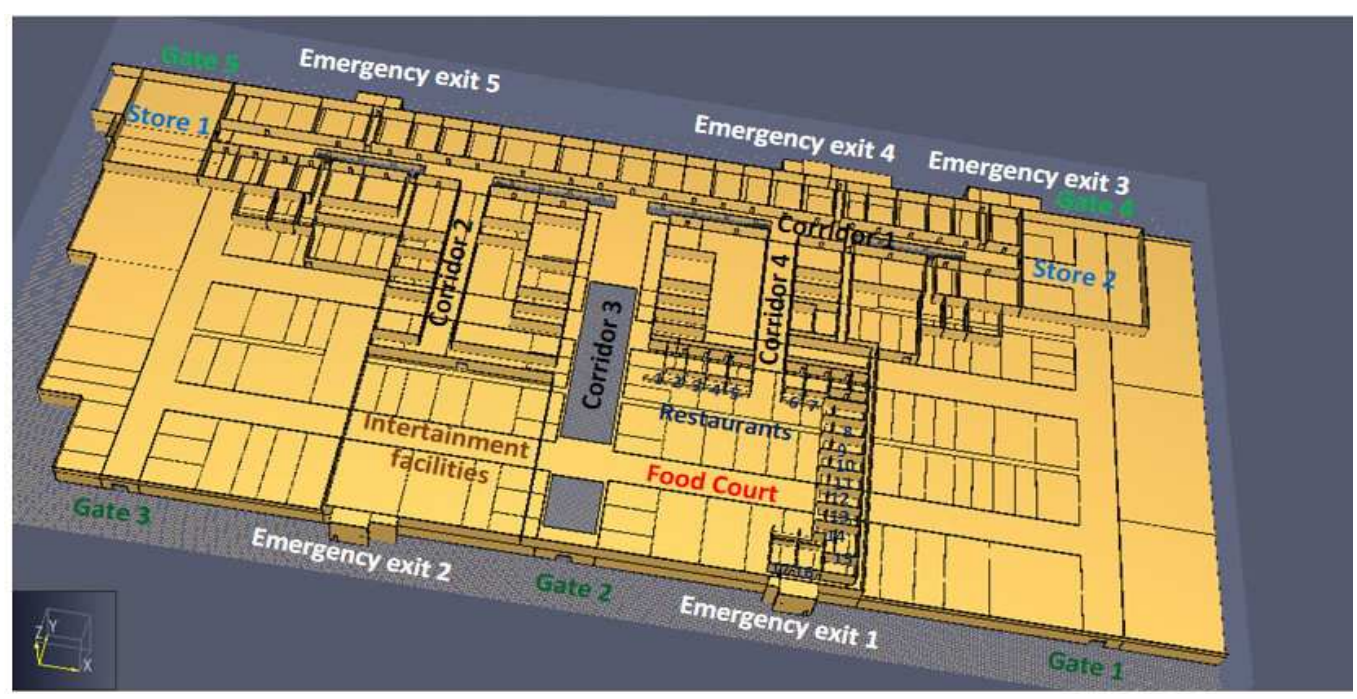

Figure 5. ain stores, corridors, and emergency exits in the upper floor.

The smoke propagation and movement with time is demonstrated in Fig. 6. The smoke movement with time can be monitored from Fig. 6 as follows:

1. After 5 seconds of fire start, smoke was still restricted to the inside of kitchen (7), Fig. 6(a).

2. After 10 seconds, the smoke spread from kitchen (7) to kitchen (8) and began to spread to the space of the food court, Fig. 6(b).

3. After 20 seconds, the smoke spread more to the space of the food court and kitchens $(6,8,9,10,11)$. Also, smoke started to spread in corridor (4), Fig. 6(c).

4. After 40 seconds, smoke spread to kitchens $(4,5,13,14)$ and completely filled kitchens $(6,8,9,10,11,12)$. It also filled half the space of the food court and spread increasingly in corridor (4), Fig. 6(d).

5. After 60 seconds, smoke filled all kitchens except $(1,2)$ and about three-fourth $(3 / 4)$ of the food court and one-third (1/3) of corridor (4), Fig. 6(e).

6. After 80 seconds, smoke filled all kitchens, all the food court space, half (1/2) of corridor (4), and started to spread in corridor (3), Fig. 6(f).

7. After 100 seconds, smoke filled all kitchens, all the food court space, half (1/2) of corridor (3), and twothirds (2/3) of corridor (4), Fig. 6(g).

8. After 120 seconds, smoke filled all kitchens, all the food court space, three-fourths (3/4) of corridor (4), more than half of corridor (3), and started to spread in the region of the entertainment facilities, Fig. 6(h).
9. After 200 seconds, smoke filled all kitchens, the food court space, corridor (4), three-fourths (3/4) of corridor (3), one-third (1/3) of the space of the entertainment facilities. Also smoke began to spread in corridors (1) and (2), and started to spread to the ground floor through escalators, Fig. 6(i).

10. After 300 seconds (5 minutes), smoke filled all kitchens, the food court space, corridors (3) and (4), half (1/2) of corridors (1) and (2), two-thirds (2/3) of the space of the entertainment facilities. Smoke also started to spread in the stores of corridors $(1,3,4)$ and downwards in corridor (1)through the escalators, Fig. 6(j).

11. After 450 seconds (7.5 minutes), smoke entirely filled all kitchens, the food court space, corridors $(2,3,4)$, more than three-fourths $(3 / 4)$ of the space of the entertainment facilities, more than three-fourths (3/4) of corridor (1), the majority of the stores of corridors $(1,3,4)$. Moreover, smoke started to spread to the stores of corridor (2) and the ground floor down corridors (1,3), Fig. 6(k).

12. After 600 seconds (10 minutes), smoke now completely filled all kitchens, the space of the food court, the space of the entertainment facilities, the majority of the stores of the corridors, in addition to one-fourth (1/4) of main store (2). Also, smoke continued to spread down the corridors $(1,3)$ to the ground floor and get out of the emergency exit (3), 
Fig. 6(1). It should be noted that pressure fans of the emergency exits were not considered in the present study.

13. After 750 seconds (12.5 minutes), smoke filled all of the spaces in the upper floor except main stores $(1,2)$. It filled just half of store (2) and one-third (1/3) of store (1). In the ground floor, the smoke entirely filled corridor (4), and started to spread to corridors $(1,2,3)$ and some stores of corridor (4). Also, smoke get to emergency exits $(1,2,3)$, Fig. $6(\mathrm{~m})$.

14. After 900 seconds (15 minutes), smoke filled all of the spaces in the upper floor except main stores $(1,2)$. Smoke filled just three-fourths (3/4) of store (2) and two-thirds $(2 / 3)$ of store (1). In the ground floor, smoke entirely filled corridor (4), and continued to spread in corridors $(1,2,3)$ and some stores of corridor (4). Also, smoke continued to get out of emergency exits (1,2,3), Fig. 6(n). Figure 6(o) shows the smoke getting out of the emergency-exit stairs (3) and (5) as can be seen from the back of the mall.

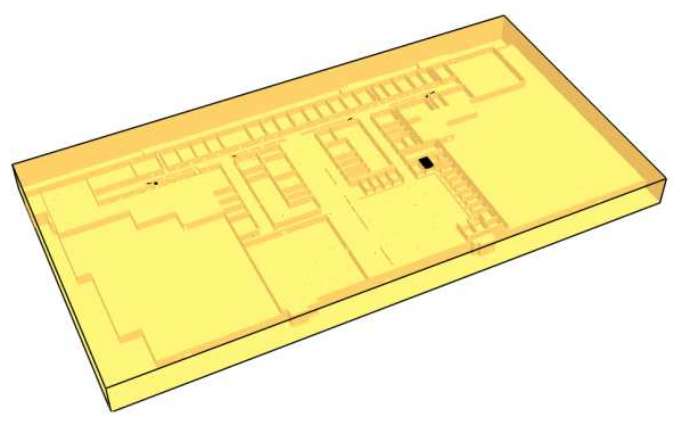

Figure 6(a). 5Sec.

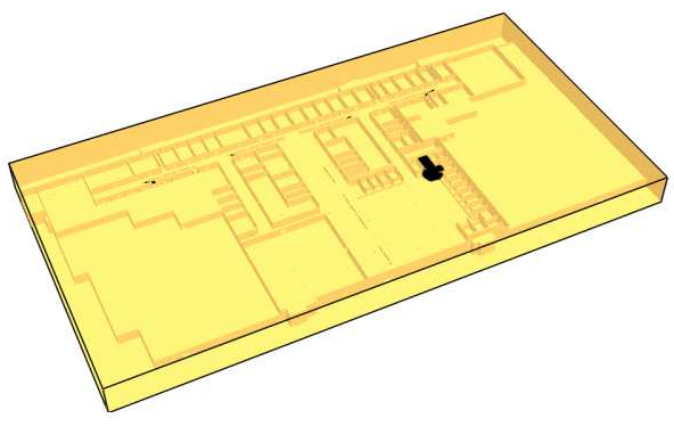

Figure 6(b). $10 \mathrm{Sec}$

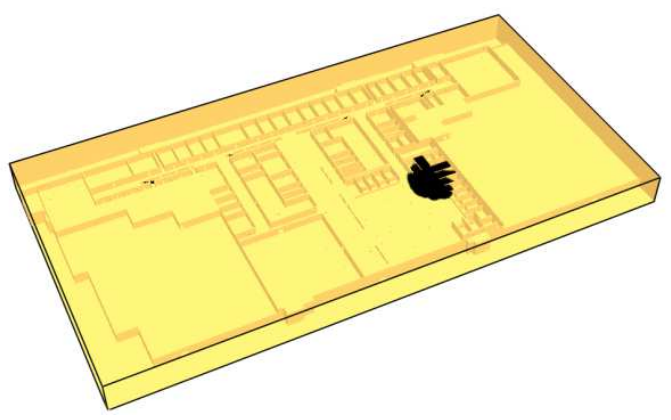

Figure 6(c). $20 \mathrm{Sec}$

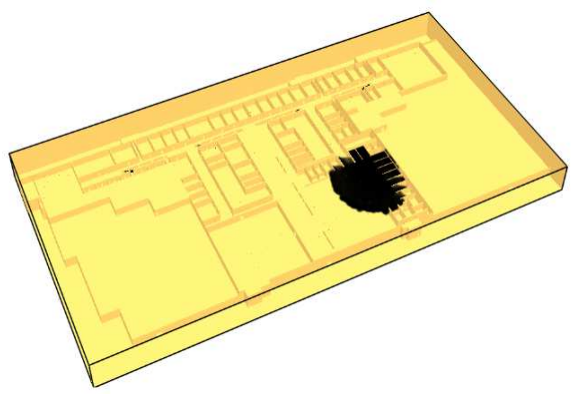

Figure 6(d). $40 \mathrm{Sec}$

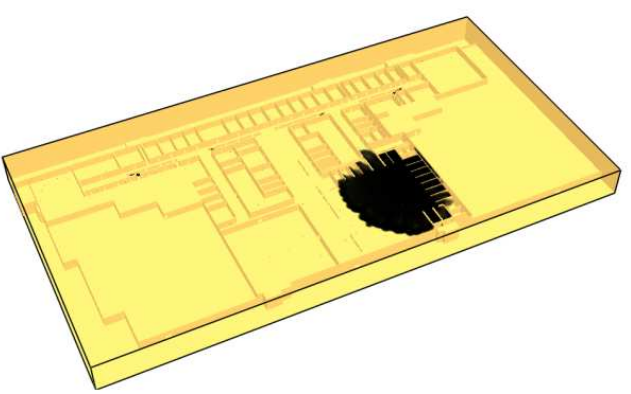

Figure 6(e). $60 \mathrm{Sec} .(1 \mathrm{Min}$.$) .$

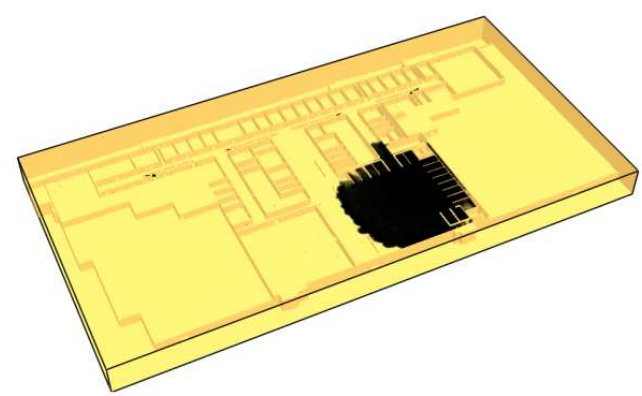

Figure 6(f). $80 \mathrm{Sec}$.

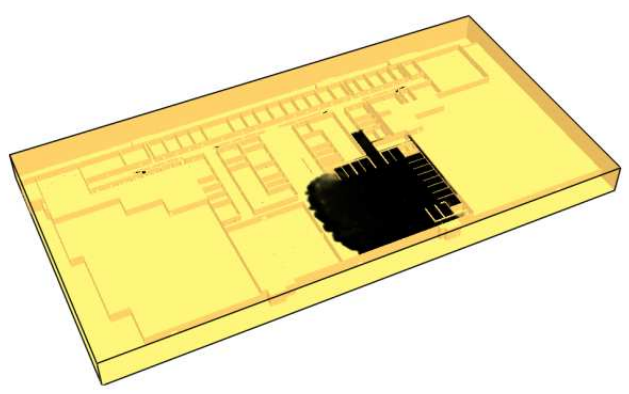

Figure 6(g). $100 \mathrm{Sec}$.

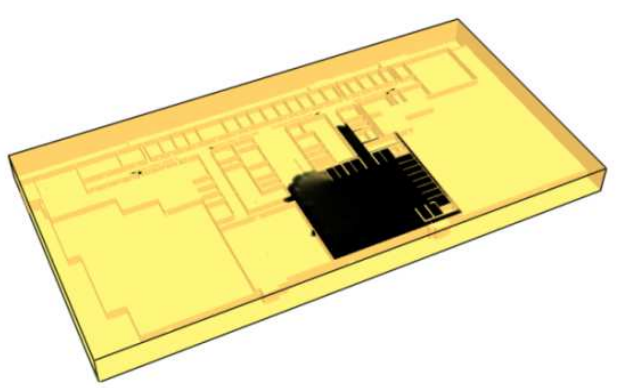

Figure 6(h). $120 \mathrm{Sec}$ (2 Min.). 


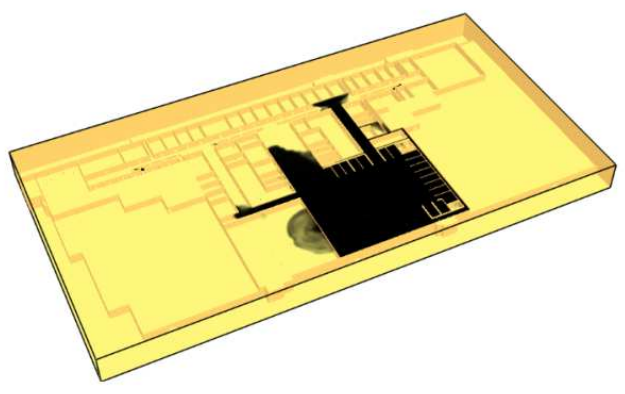

Figure 6(i). $200 \mathrm{Sec}$.

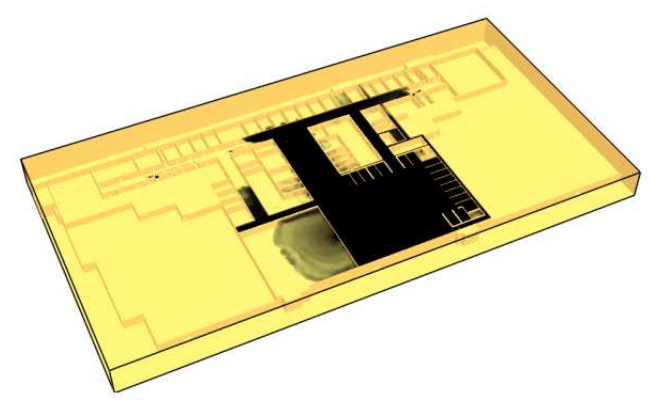

Figure 6(j). 300 Sec. (5 Min.).

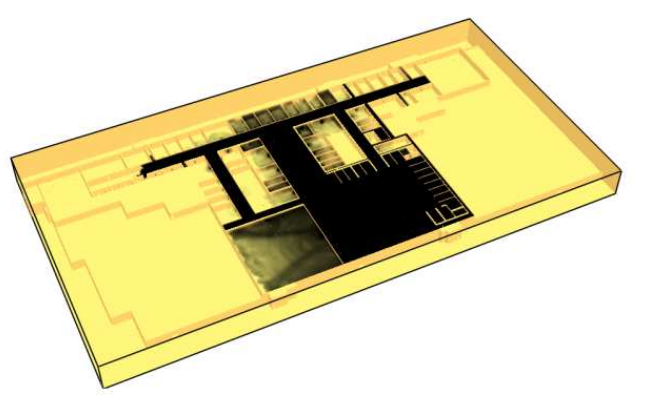

Figure 6(k). 450 Sec. (7.5 Min.).

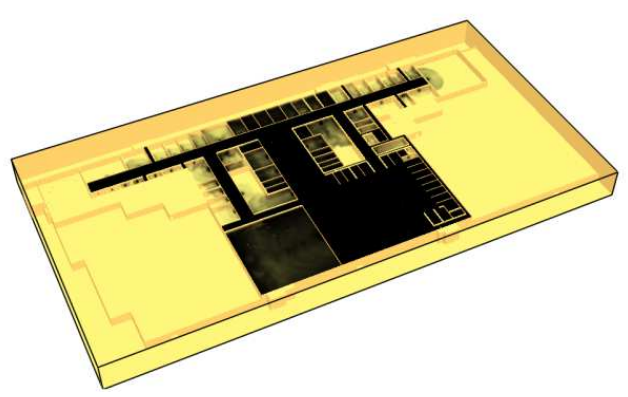

Figure 6(l). 600 Sec. (10 Min.).

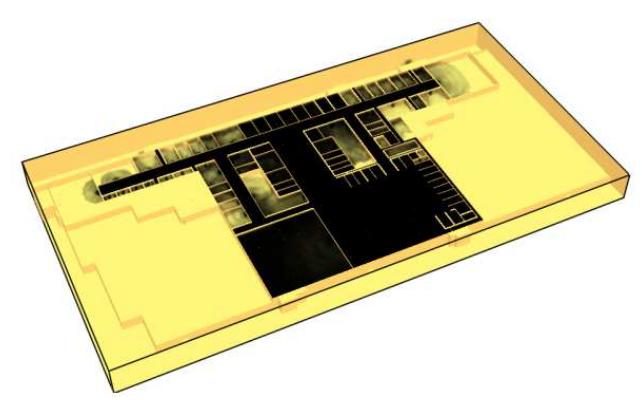

Figure 6(m). 750 Sec. (12.5Min.).

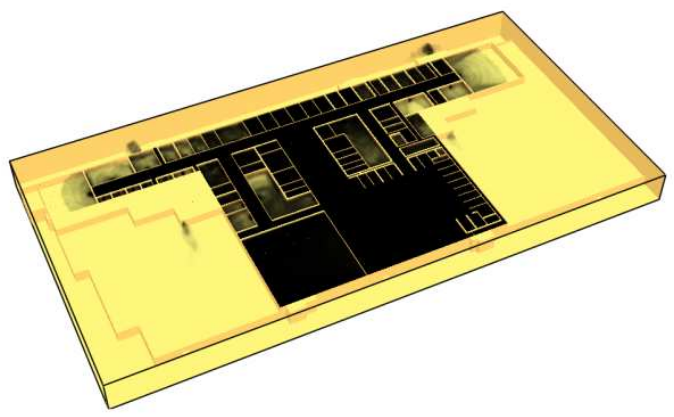

Figure 6(n). 900 Sec. (15 Min.).

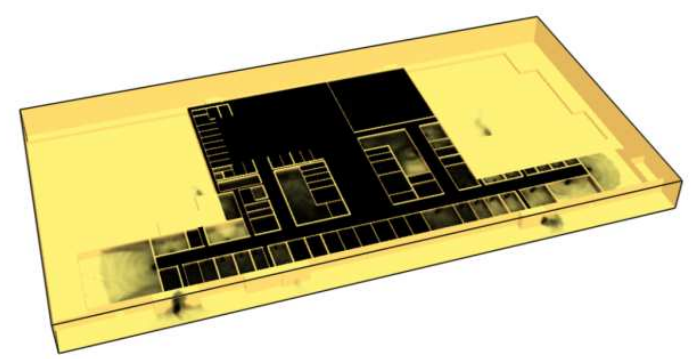

Figure 6(o). Smoke getting out of the emergency-exit stairs 3 and 5 (back view of the mall).

Figure 6. Smoke propagation with time, Case (1).

Figure 7 shows the temperature distribution near the area of fire. Figure 7(a) shows the temperature distribution in a vertical plane passing through the fire spot and in the normal direction to the mall front. It is clear that the maximum temperature of $105^{\circ} \mathrm{C}$ is reached in the fire spot. Figure 7(b) shows the temperature distribution in another vertical plate, which is parallel to the plane of Fig. 7(a) but $10 \mathrm{~m}$ away from the fire spot. The maximum temperature is $45^{\circ} \mathrm{C}$. Figure 7 (c) shows the temperature distribution in a vertical plane parallel to the mall front and $15 \mathrm{~m}$ away from the fire spot. The maximum temperature is about $30^{\circ} \mathrm{C}$. Figure $7(\mathrm{~d})$ indicates that the sprinkles in the fire region worked successfully.

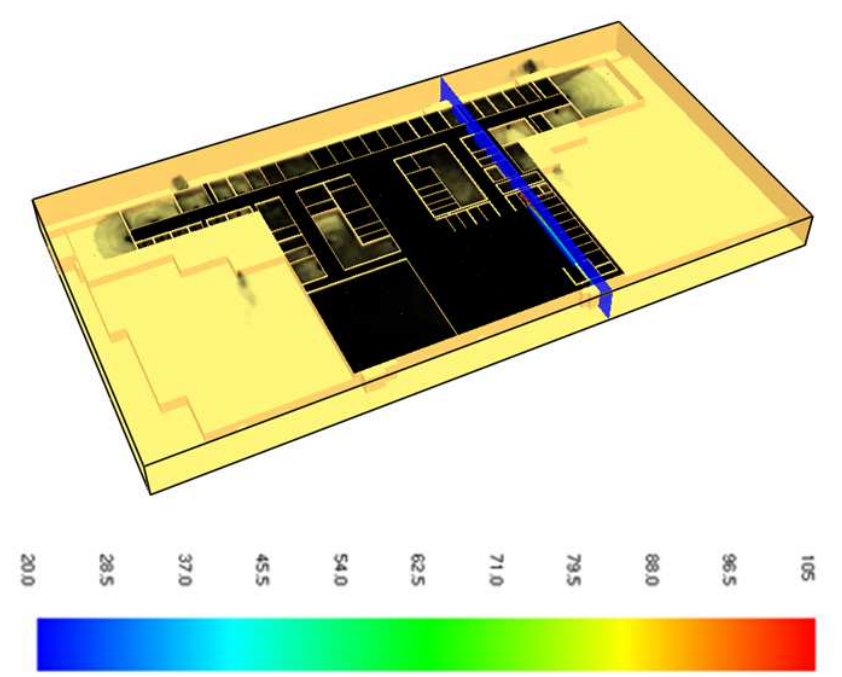

Figure 7(a). Temperature distribution in a vertical plane passing through the fire spot and in the normal direction to the mall front. 


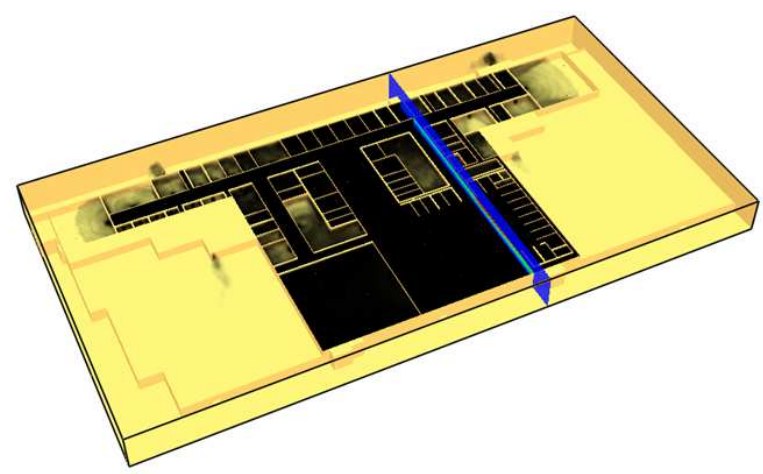

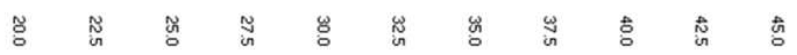

Figure 7(b). Temperature distribution in a vertical plane $10 \mathrm{~m}$ away from the fire spot and in the normal direction to the mall front.

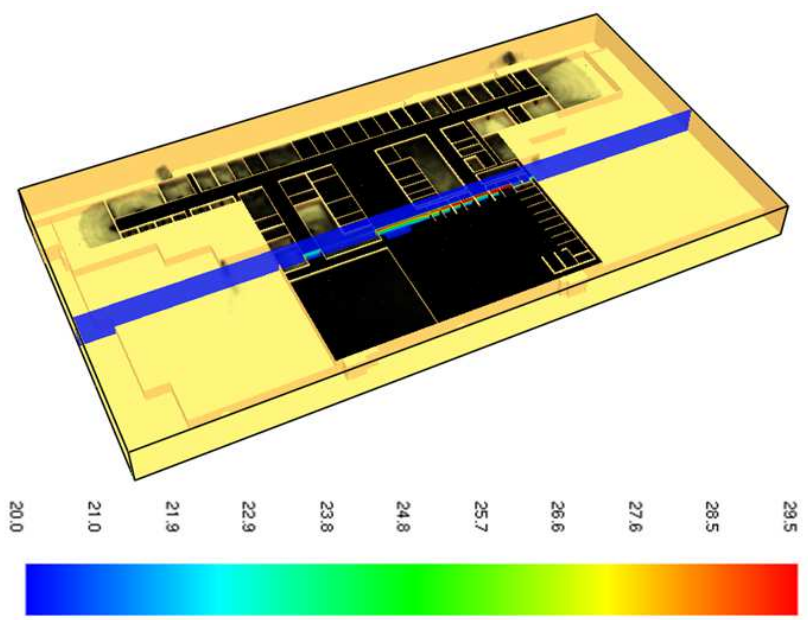

Figure 7(c). Temperature distribution in a vertical plane parallel to the mall front and $15 \mathrm{~m}$ away from the fire spot.

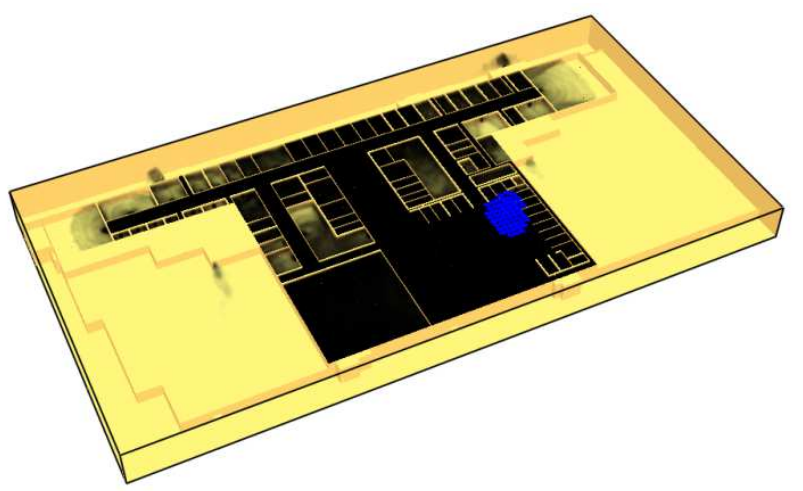

Figure $7(d)$. The working sprinkles in the fire region.

Figure 7. Temperature distribution near the area of fire, Case (1).

\subsubsection{Case Study (2)}

The second case study concerned a fire ignition at main store (2)in the upper floor, Fig. 5. The smoke propagation/movement with time is demonstrated in Fig. 8. The smoke movement with time can be monitored from Fig.
8 as follows:

1. After 5 seconds of fire start, smoke just began to spread in store (2), Fig. 8(a).

2. After 10 seconds, smoke filled one-third $(1 / 3)$ of store (2), Fig. 8(b).

3. After 20 seconds, smoke filled more than threefourths (3/4) of store (2). Smoke was still trapped in store (2), Fig. 8(c).

4. After 40 seconds, smoke completely filled store (2) and started to spread to corridor (1), Fig. 8(d).

5. After 60 seconds, smoke completely filled store (2), continued spreading in corridor (1), and started to spread to the first escalator in front of store (2), Fig. 8(e).

6. After 80 seconds, smoke completely filled store (2), one-fourth (1/4) of corridor (1), and most of the space of the first escalator in front of store (2), Fig. 8(f).

7. After 100 seconds, smoke completely filled store (2), the space of the first escalator in front of store (2), and more than one-fourth (1/4) of corridor (1), Fig. $8(\mathrm{~g})$.

8. After 120 seconds, smoke completely filled store (2), the space of the first escalator in front of store (2), and more than one-third (1/3) of corridor (1). Also, smoke approached the next escalator, Fig. 8(h).

9. After 200 seconds, smoke completely filled store (2), the space of the two escalators in front of store (2), half $(1 / 2)$ of corridor (1). Also, smoke started to spread in corridor (4) and in the corridor that leads to the mosque and the rest (WC) rooms, Fig. 8(i).

10. After 300 seconds (5 minutes), smoke completely filled store (2), the space of the three escalators in front of store (2), corridor (4), the corridor that leads to the mosque and rest (WC) rooms. Also, smoke filled two-thirds (2/3) of corridor (1) and approached the food court zone, Fig. 8(j).

11. After 450 seconds ( 7.5 minutes), smoke completely filled store (2), the three escalators in front of store (2), corridors 3 and 4 , the corridor that leads to the mosque and rest rooms. Also, smoke filled threefourths (3/4) of corridor (1) and one-third of corridor (2), and started to spread in the space of the food court, Fig. 8(k).

12. After 600 seconds (10 minutes), smoke completely filled store (2), corridor (1), the four escalators that exist in corridor (1), corridors(3) and (4). Also, smoke filled three-fourths (3/4) of corridor (2) and one-fourth(1/4) of the space of the food court. Moreover, smoke started to spread in the mosque and rest (WC) rooms adjacent to store (2), Fig. 8(1).

13. After 750 seconds (12.5 minutes), smoke completely filled store (2), corridors $(1,2,3,4)$, the corridors that lead to the mosque and rest (WC) rooms on that floor, the four escalators that exist in corridor (1). Also, smoke filled three-fourths(3/4) of the space of the food court and spread to the majority of the kitchens and the stores of all corridors, Fig. 8(m). 
14. After 900 seconds (15 minutes), smoke completely filled store (2), all corridors, all kitchens, the four escalators that exist in corridor (1), the entire space of the food court, and the majority of stores of all corridors. Moreover, smoke started to spread to the space of the entertainment facilities, Fig. 8(n). Figure 8 (o) shows the smoke getting out of the emergencyexit stairs (3) and (4) as can be seen from the back of the mall.

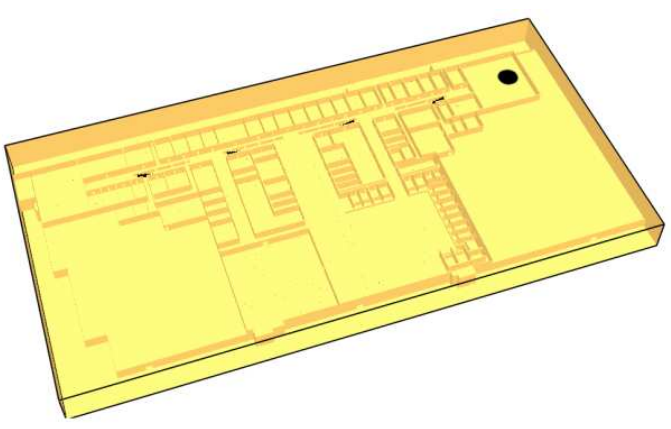

Figure 8(a). $5 \mathrm{Sec}$.

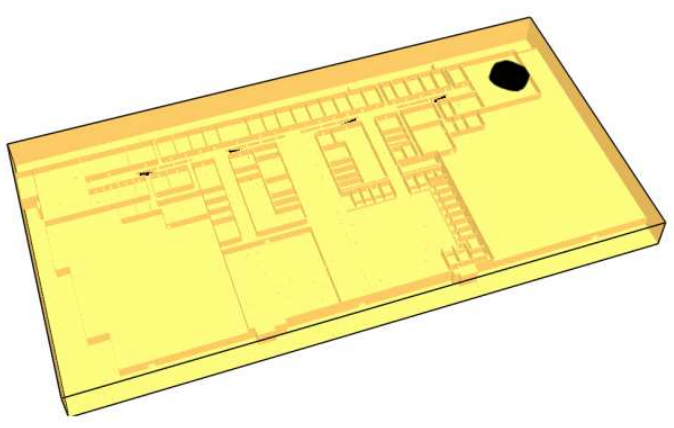

Figure 8(b). $10 \mathrm{Sec}$

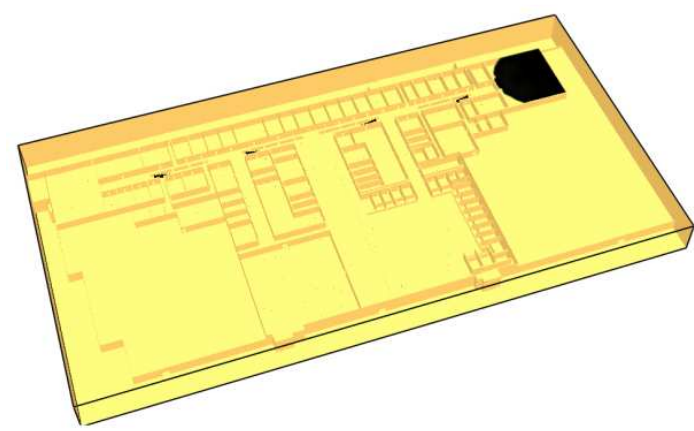

Figure 8(c). $20 \mathrm{Sec}$

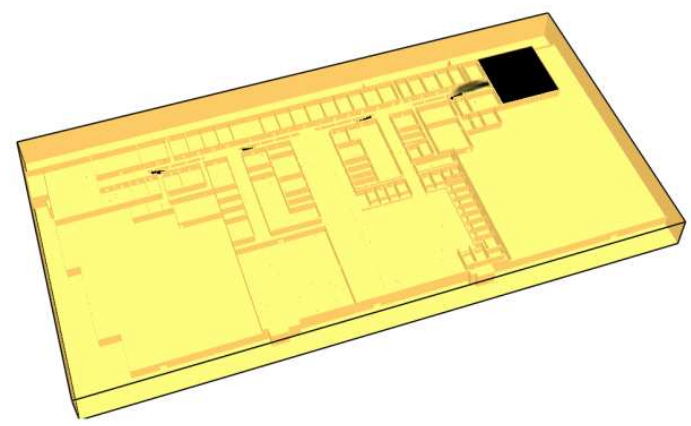

Figure 8(d). $40 \mathrm{Sec}$

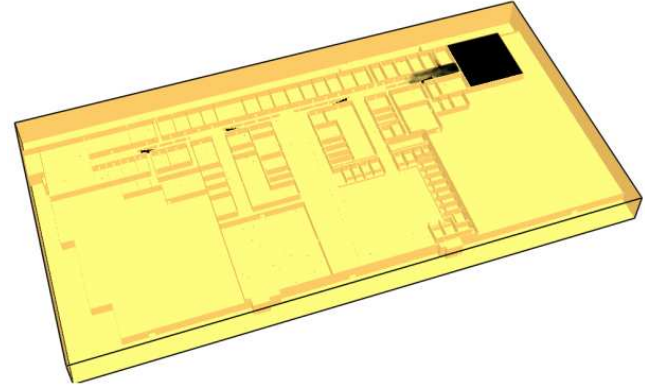

Figure 8(e). 60 Sec. (1 Min.)

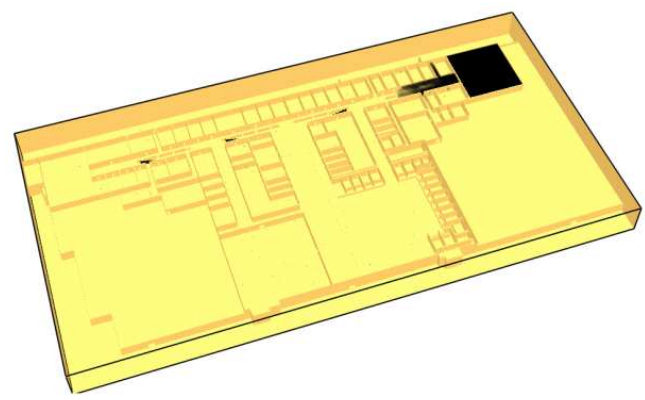

Figure 8(f). $80 \mathrm{Sec}$.

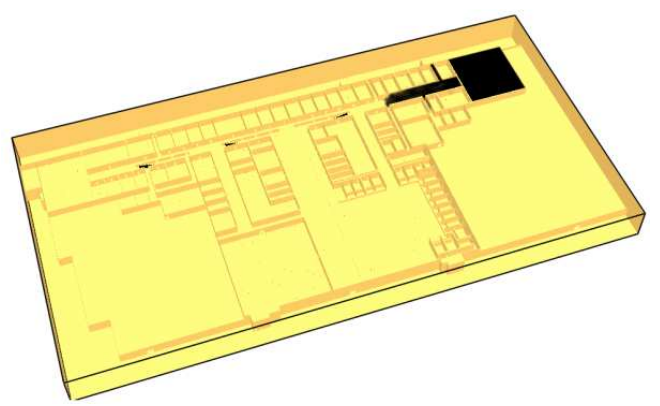

Figure 8(g). $100 \mathrm{Sec}$.

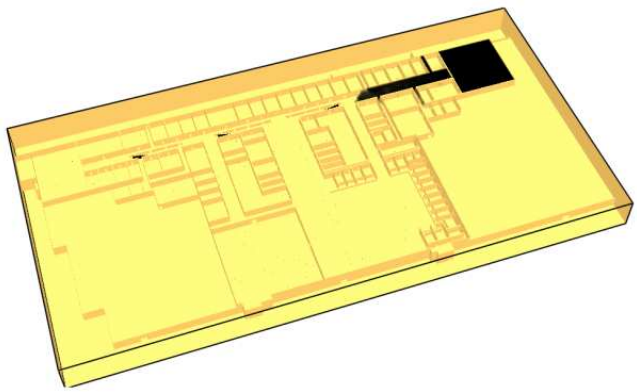

Figure 8(h). 120 Sec. (2 Min.).

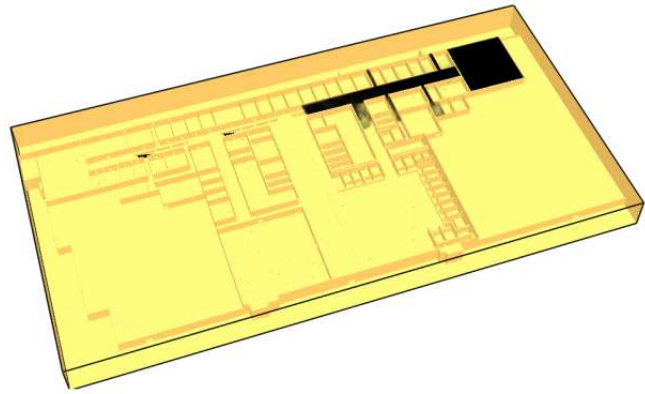

Figure 8(i). $200 \mathrm{Sec}$ 


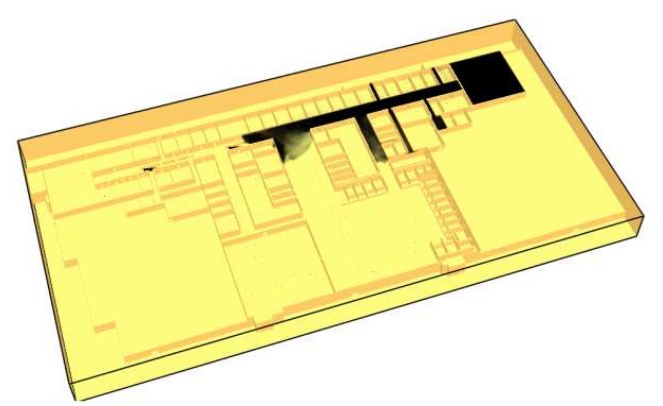

Figure 8(j). 300 Sec. (5 Min.)

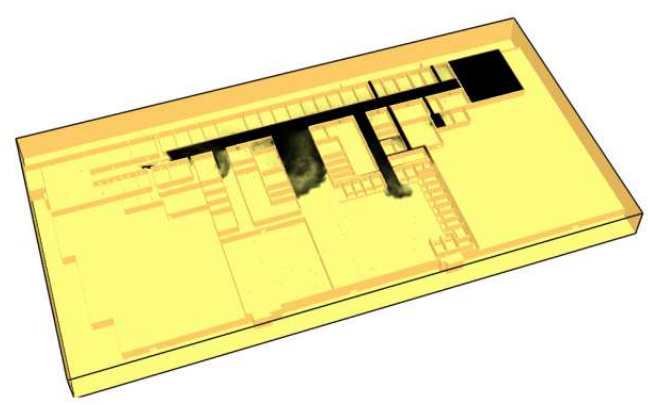

Figure 8(k). 450 Sec. (7.5 Min.).

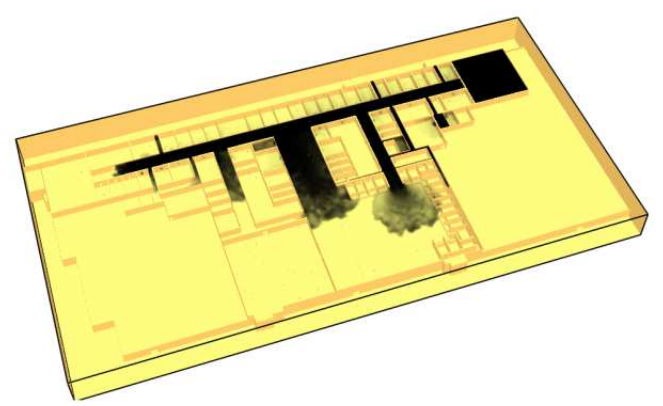

Figure 8(l). 600 Sec. (10 Min.)

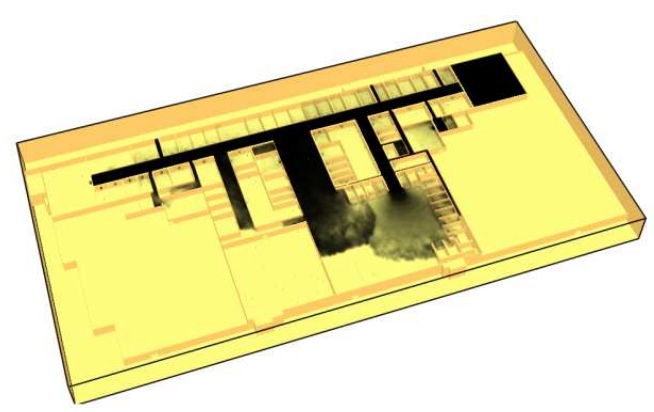

Figure 8(m). $750 \mathrm{Sec}$. (12.5 Min.).

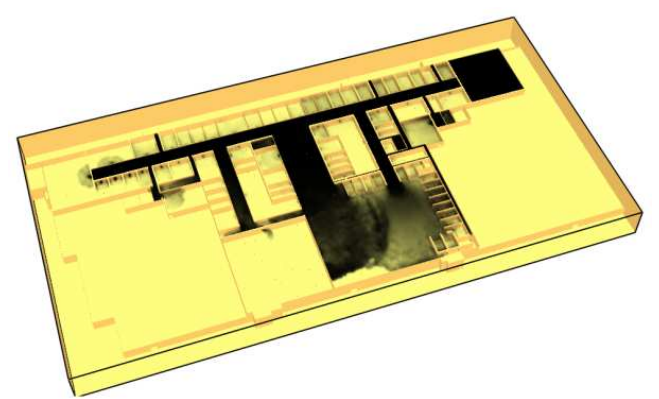

Figure 8(n). $900 \mathrm{Sec} .(15 \mathrm{Min}$.).

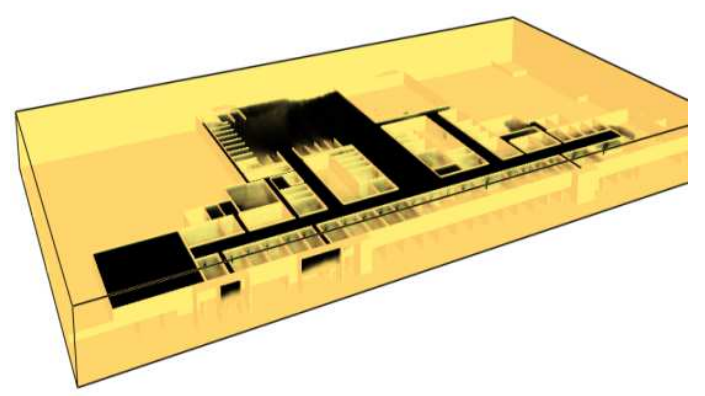

Figure 8(o). Smoke getting out of the emergency-exit stairs 3 and 4 (Back view of the mall).

Figure 8. Smoke propagation with time, Case 2.

Figure 9 shows the temperature distribution near the area of fire. Figure 9(a) shows the temperature distribution in a vertical plane passing through the fire spot and in the normal direction to the mall front. It is clear that the maximum temperature of $105^{\circ} \mathrm{C}$ is reached in the fire spot. Figure 9 (b) shows the temperature distribution in another vertical plate, which is parallel to the plane of Fig. 9(a) but $10 \mathrm{~m}$ away from the fire spot. The maximum temperature is $90^{\circ} \mathrm{C}$. Figure $9(\mathrm{c})$ shows the temperature distribution in a vertical plane parallel to the mall front and $15 \mathrm{~m}$ away from the fire spot. The maximum temperature is about $80^{\circ} \mathrm{C}$. Figure 9 (d) indicates that the sprinkles in the fire region worked successfully.

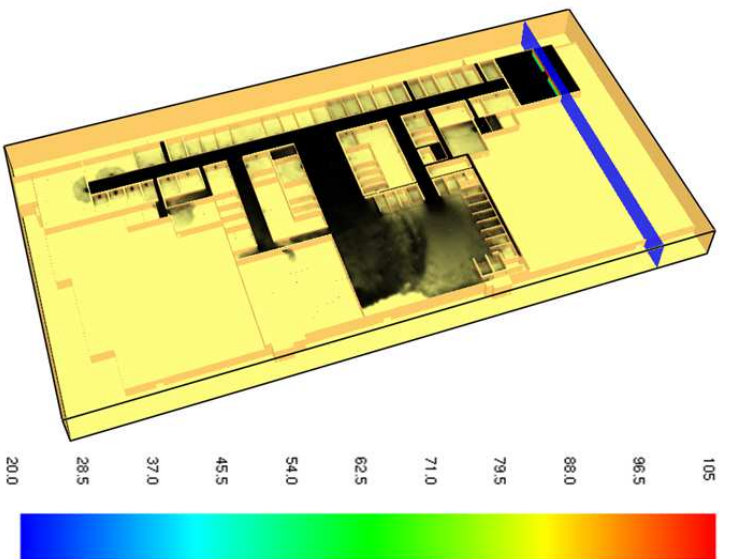

Figure 9(a). Temperature distribution in a vertical plane passing through the fire spot and in the normal direction to the mall front.

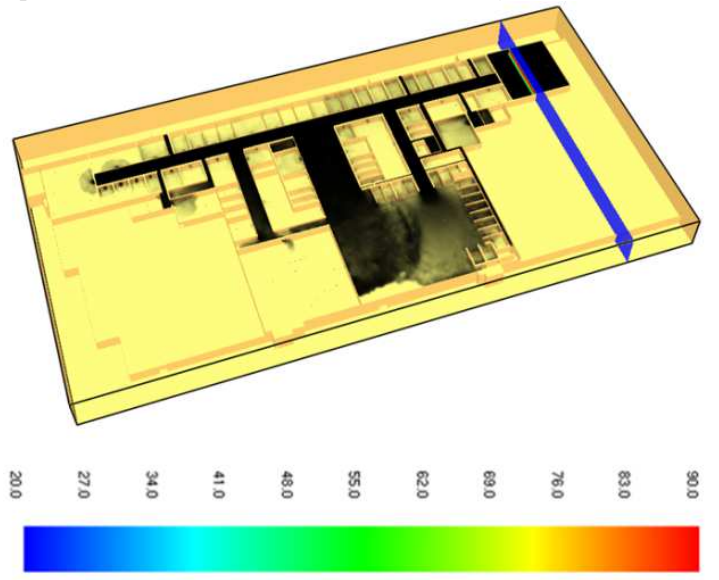

Figure 9(b). Temperature distribution in a vertical plane $10 \mathrm{~m}$ away from the fire spot and in the normal direction to the mall front. 


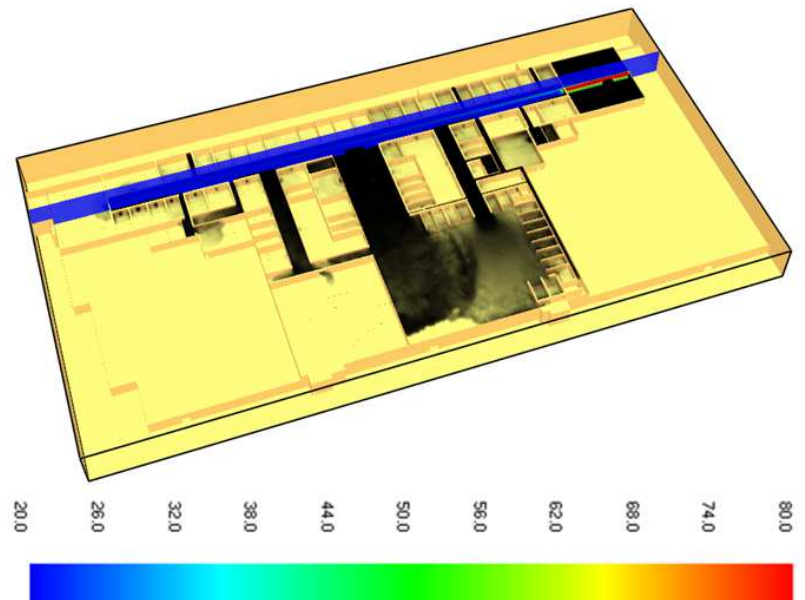

Figure 9(c). Temperature distribution in a vertical plane parallel to the mall front and $15 \mathrm{~m}$ away from the fire spot.

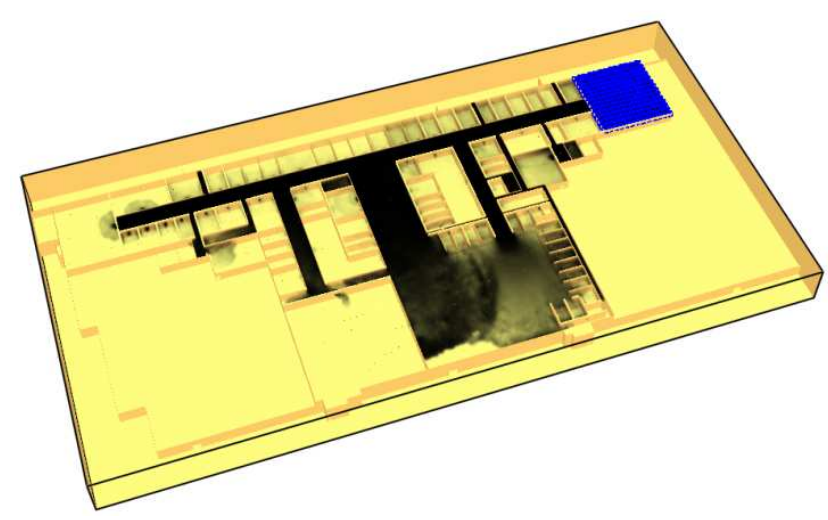

Figure 9(d). The working sprinkles in the fire region.

Figure 9. Temperature distribution near the area of fire, Case(2).

\subsubsection{Case Study (3)}

The third case study concerned a fire ignition at main store (3)in the ground floor. Again, to facilitate the following of the smoke propagation and movement with time, the important parts of the ground floor (main stores, gates, corridors, emergency exits, etc.) are notified and numbered as can be seen in Fig. 10.

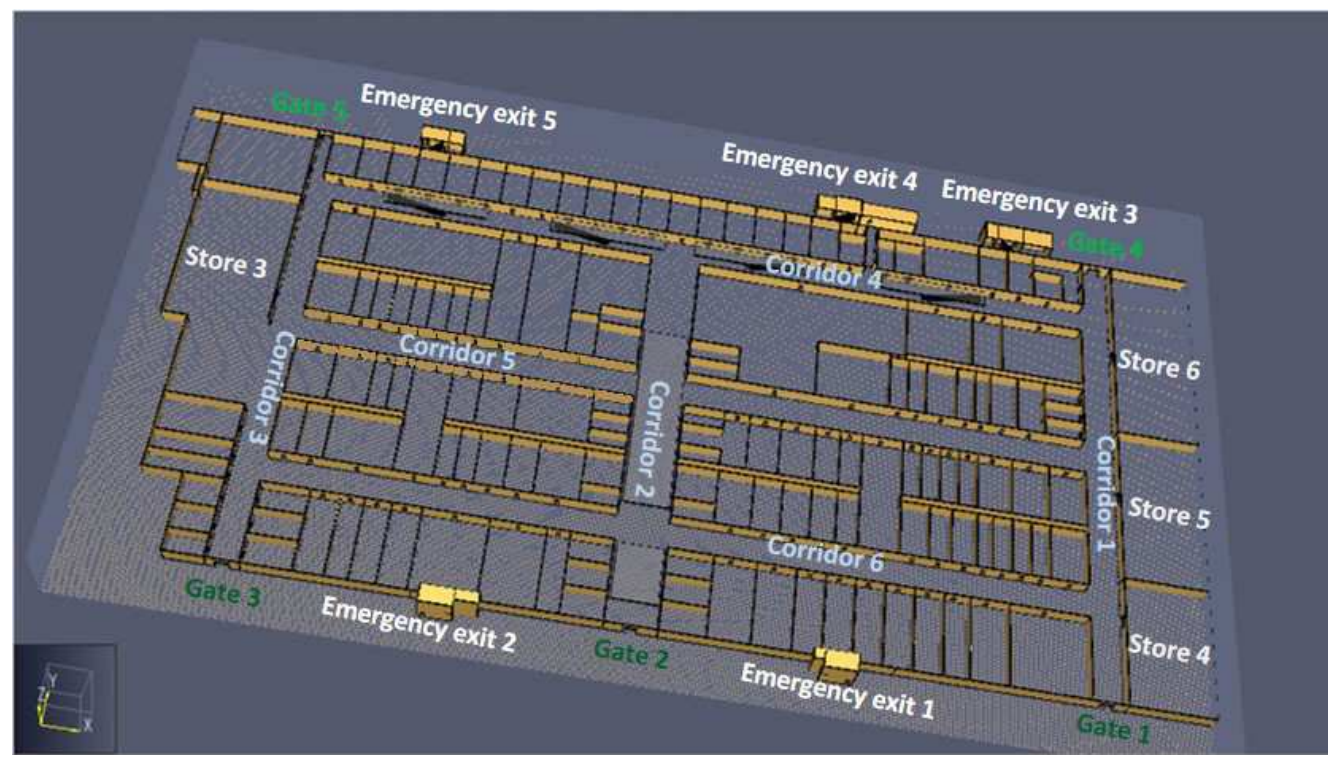

Figure 10. Main stores, corridors, and gates in the ground floor.

The smoke propagation/movement with time is demonstrated in Fig. 11. The smoke movement with time can be monitored from Fig. 11 as follows:

1. After 5 seconds of fire start, smoke started to spread inside store (3), Fig. 11(a).

2. After 10 seconds, smoke propagated in store (3) and was still trapped inside it, Fig. 11(b).

3. After 20 seconds, smoke filled more than half of store (3) and still trapped inside it, Fig. 11(c).

4. After 40 seconds, smoke filled more than threefourths (3/4) of store (3) and started to spread in corridor (3), Fig. 11(d).

5. After 60 seconds, smoke completely filled store (3), filled one-third (1/3) of corridor (3), and started to spread in corridor (5), Fig. 11(e).

6. After 80 seconds, smoke completely filled store (3), more than half of corridor (3), and continued to spread in corridor (5), Fig. 11(f).

7. After 100 seconds, smoke filled completely store (3), three-fourths (3/4) of corridor (3), continued to spread in corridor (5), and started to spread in corridor (6) and to the stores adjacent to store (3) in corridor (3), Fig. 11(g).

8. After 120 seconds, smoke filled completely store (3), more than three-fourths (3/4) of corridor (3), and continued to spread in corridors (5) and (6) and the stores of corridor (3), Fig. 11(h).

9. After 200 seconds, smoke completely filled store (3), 
corridor (3) and the stores in corridor (3), about onethird (1/3) of corridor (5), about one-fourth (1/4) of corridor (6), and started to spread to the stores of corridors(5) and (6) and get out through gates(3) and (5), Fig. 11(i).

10. After 300 seconds (5 minutes), smoke completely filled store (3), corridor (3), all stores of corridor (3), half $(1 / 2)$ of corridors (5) and (6), some stores in the first half of corridors (5) and (6), and about onefourth (1/4) of corridor (4). Also, it started to spread in corridor (2) and continued to get out of gates (3) and (5), Fig. 11(j).

11. After 450 seconds (7.5 minutes), smoke completely filled store (3), corridors(2) and (3), all stores in corridor (3), two-thirds (2/3) of corridor (6), half $(1 / 2)$ of corridor (5), the majority of stores in the first half of corridors (5) and (6), one-third (1/3) of corridor (4), and continued to get out of gates (3) and (5), Fig. $11(\mathrm{k})$.

12. After 600 seconds (10 minutes), smoke completely filled store (3), corridors (2) and (3), all stores in corridors (2) and (3), three-fourths (3/4) of corridors (5) and (6), the majority of stores in the first half of corridors (4), (5) and (6), two-thirds (2/3) of corridor (4). Also, smoke continued to get out of gates (3) and (5) and started to get out of gate (2), Fig. 11(1).

13. After 750 seconds (12.5 minutes), smoke completely filled store (3), corridors (2) and (3), all stores in corridors (2) and (3), the majority of other corridors except corridor (1), the majority of stores in corridors (5) and (6), some stores in corridor (4). Also, smoke continued to get out through gates (2),(3) and (5), Fig. 11(m).

14. After 900 seconds (15 minutes), smoke completely filled store (3), corridors (2), (3) and (6), and all stores in corridors (2), and (3). Also, smoke filled the majority of stores in corridor (6), three-fourths (3/4) of corridors (4) and (5), and the majority of stores in them, Fig. 11(n). Figure 11(o) shows the smoke getting out through gates (2) and (3). Figure 11p shows the smoke getting out through gate (5) as seen from the back of the mall.

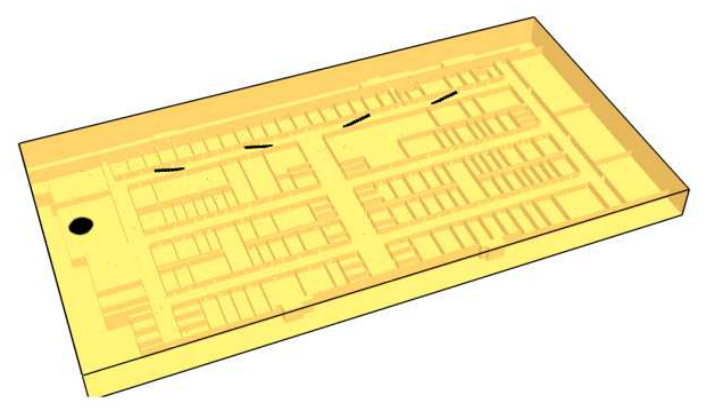

Figure 11(a). $5 \mathrm{Sec}$.

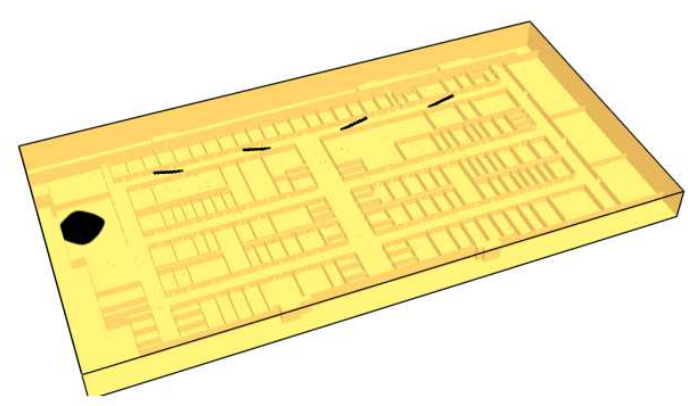

Figure 11(b). $10 \mathrm{Sec}$.

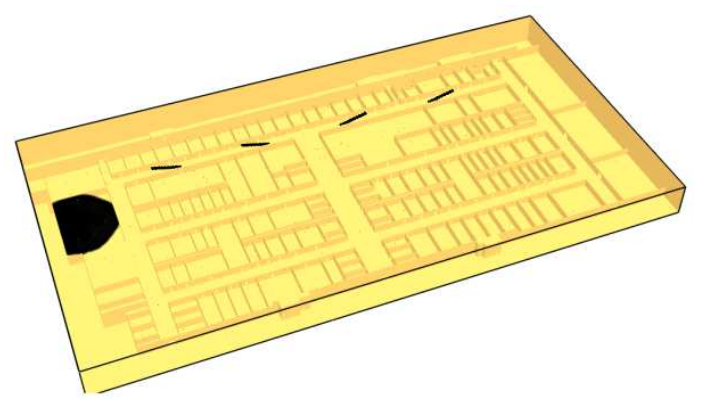

Figure 11(c). $20 \mathrm{Sec}$

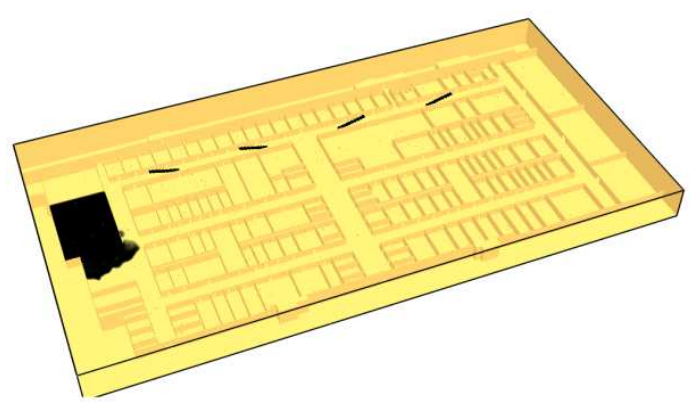

Figure 11(d). $40 \mathrm{Sec}$

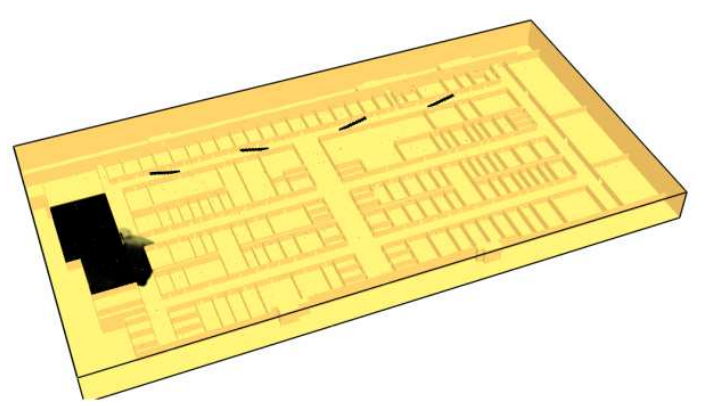

Figure 11(e). $60 \mathrm{Sec} .(1 \mathrm{Min}$.$) .$

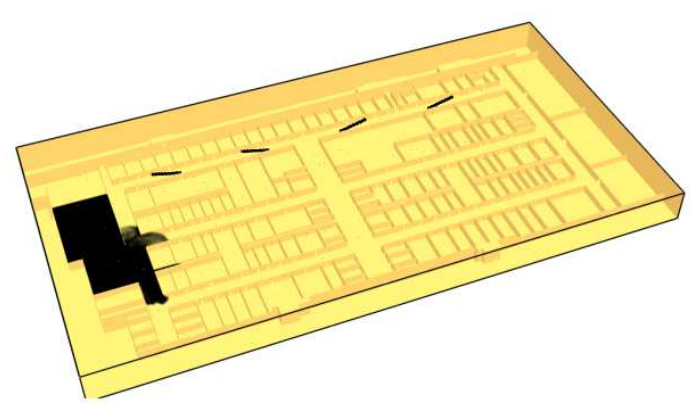

Figure 11(f). $80 \mathrm{Sec}$. 


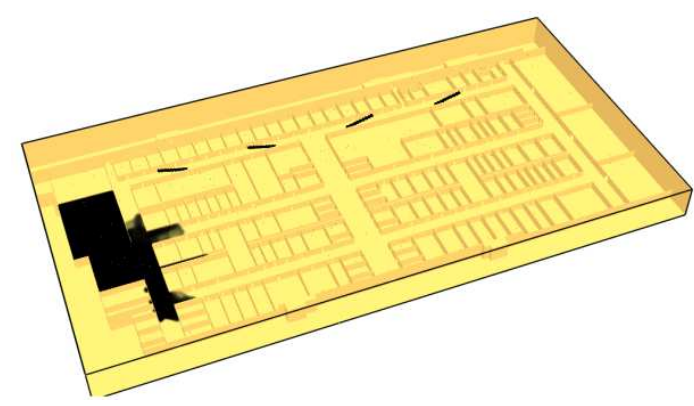

Figure 11(g). $100 \mathrm{Sec}$.

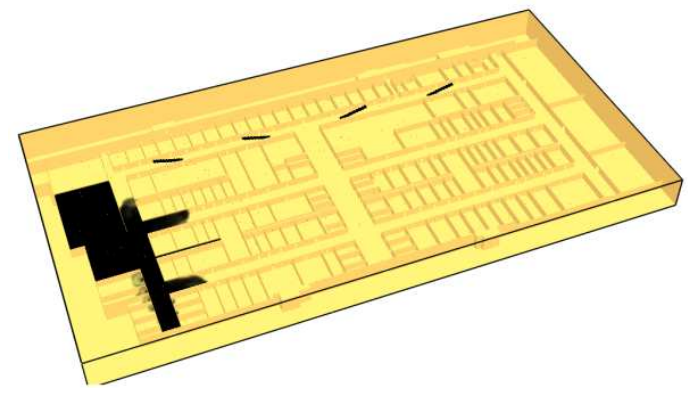

Figure 11(h). 120 Sec. (2 Min.).

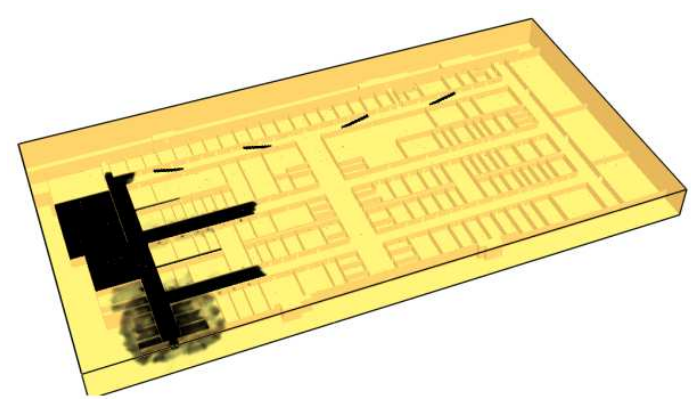

Figure 11(i). $200 \mathrm{Sec}$.

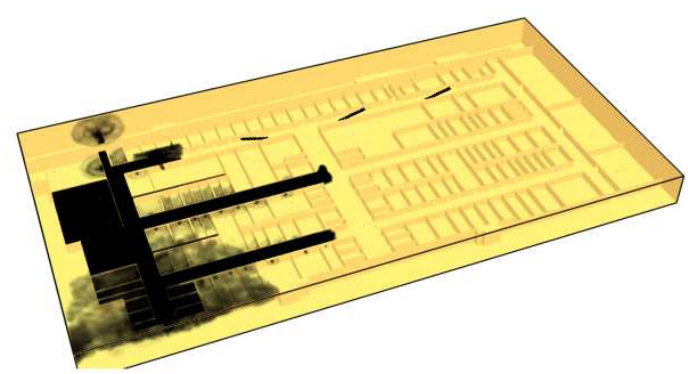

Figure 11(j). 300 Sec. (5 Min.).

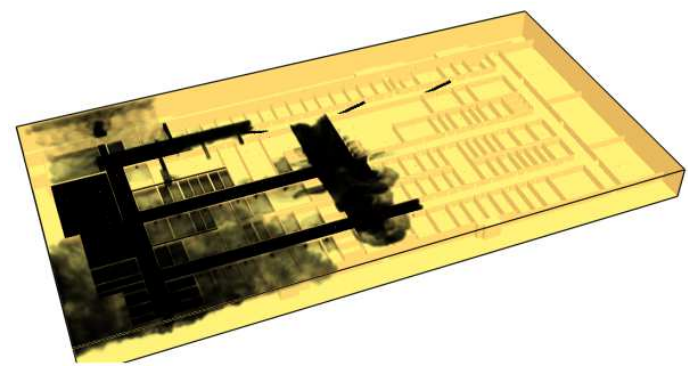

Figure 11(k). 450 Sec. (7.5 Min.).

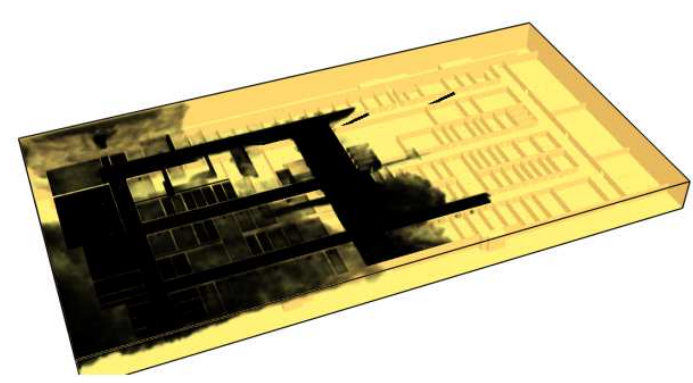

Figure 11(l). 600 Sec. (10 Min.)

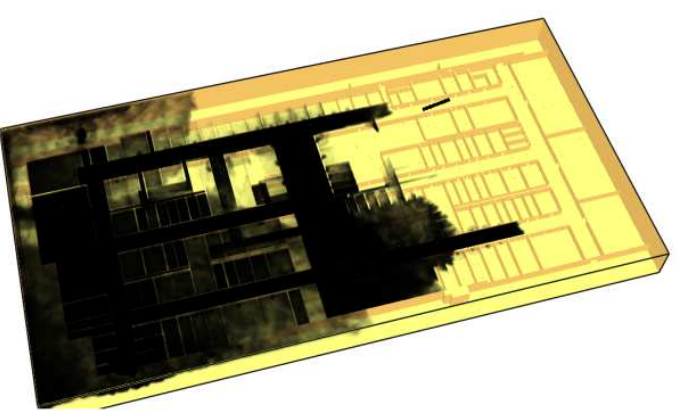

Figure 11(m). 750 Sec. (12.5 Min.).

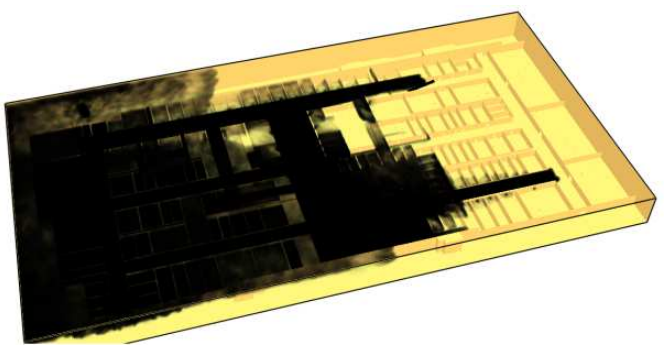

Figure 11(n). $900 \mathrm{Sec} .(15 \mathrm{Min}$.$) .$

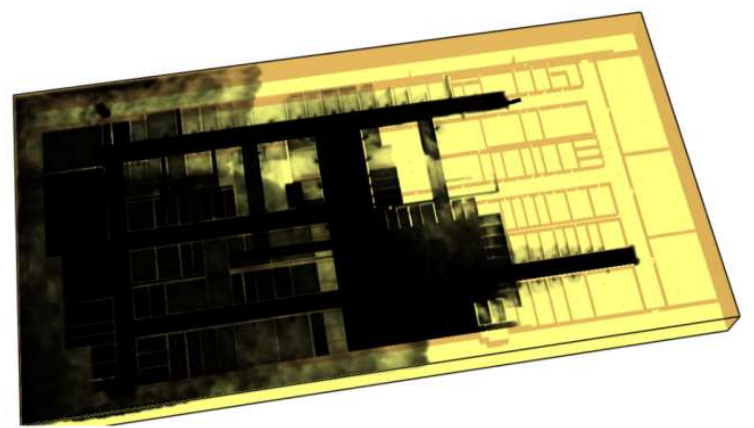

Figure 11(o). Smoke getting out through gates (2) and (3).

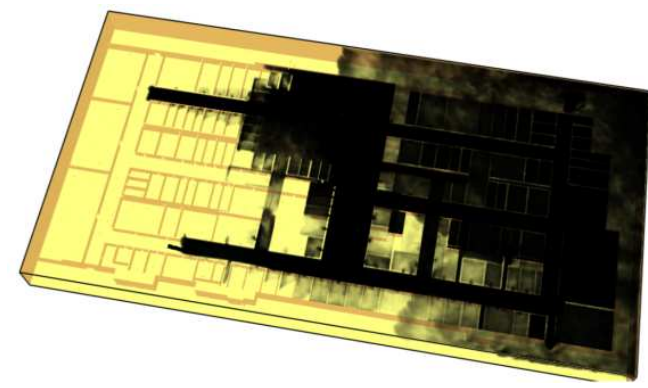

Figure 11(p). Smoke getting out through gate (5) (Back view of the mall).

Figure 11. Smoke propagation with time, Case (3). 
Figure 12 shows the temperature distribution near the area of fire. Figure 12(a) shows the temperature distribution in a vertical plane passing through the fire spot and in the normal direction to the mall front. It is clear that the maximum temperature of $85^{\circ} \mathrm{C}$ is reached in the fire spot. Figure 12(b) shows the temperature distribution in another vertical plate, which is parallel to the plane of Fig. 12(a) but $10 \mathrm{~m}$ away from the fire spot. The maximum temperature is $65^{\circ} \mathrm{C}$. Figure 12(c) shows the temperature distribution in a vertical plane parallel to the mall front and $15 \mathrm{~m}$ away from the fire spot. The maximum temperature is about $40^{\circ} \mathrm{C}$. Figure $12(\mathrm{~d})$ indicates that the sprinkles in the fire region worked successfully.

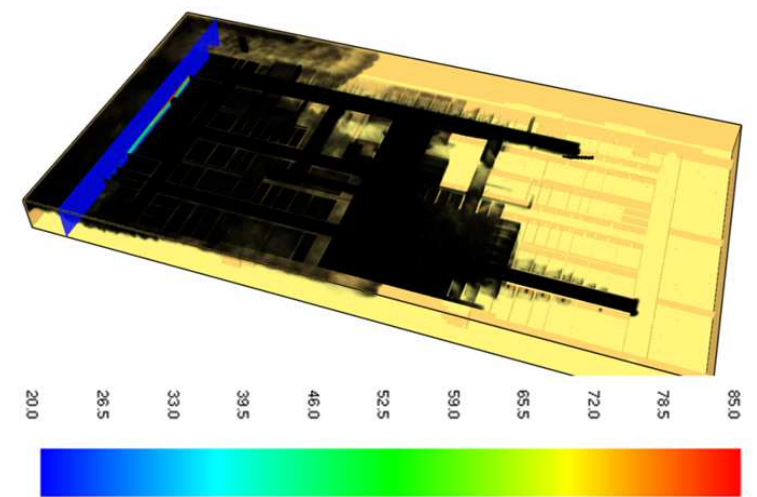

Figure 12(a). Temperature distribution in a vertical plane passing through the fire spot and in the normal direction to the mall front.

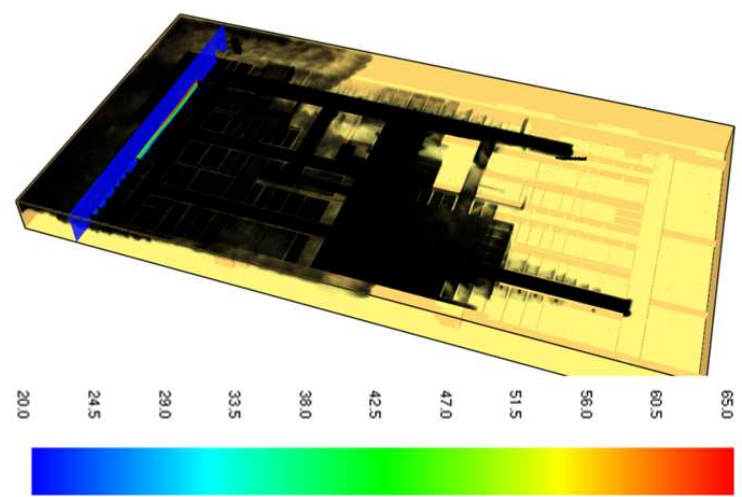

Figure 12(b). Temperature distribution in a vertical plane $10 \mathrm{~m}$ away from the fire spot and in the normal direction to the mall front.

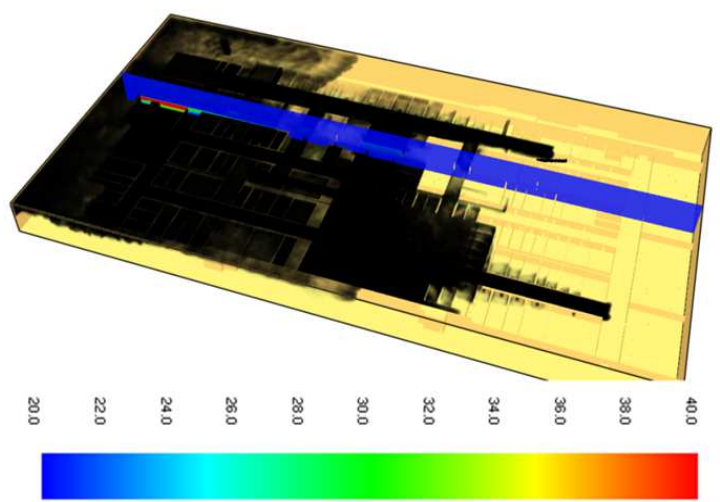

Figure 12(c). Temperature distribution in a vertical plane parallel to the mall front and $15 \mathrm{~m}$ away from the fire spot.

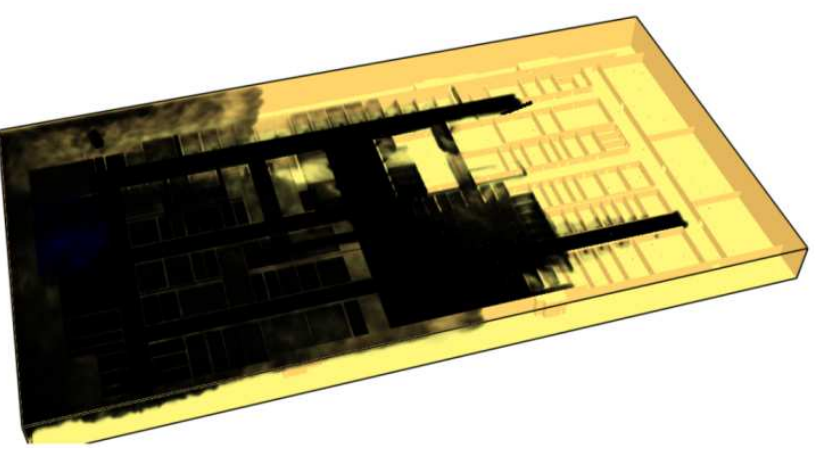

Figure 12(d). The working sprinkles in the fire region.

Figure 12. Temperature distribution near the area of fire, Case (3).

\subsubsection{Case Study (4)}

The fourth case study concerned a fire ignition at main store (5) in the ground floor, Fig. 10. The smoke propagation and movement with time is demonstrated in Fig. 13. The smoke movement with time can be monitored from Fig. 13 as follows:

1. After 5 seconds of fire start, smoke started to spread inside store (5), Fig. 13(a).

2. After 10 seconds, smoke propagated in store (5) and was still trapped inside it, Fig. 13(b).

3. After 20 seconds, smoke approximately filled threefourths (3/4) of store (5) and started to spread outside the store through its main door, Fig. 13(c).

4. After 40 seconds, smoke completely filled store (5) and moved outside the store through its main door in corridor (1), Fig. 13(d).

5. After 60 seconds, smoke completely filled store 5 and continued to spread in corridor (1), Fig. 13(e).

6. After 80 seconds, smoke completely filled store (5), approximately filled one-fourth (1/4) of corridor (1), and started to spread in corridor 5, Fig. 13(f).

7. After 100 seconds, smoke completely filled store (5), approximately filled one-third (1/3) of corridor (1), and continued to spread in corridor (5), Fig. 13(g).

8. After 120 seconds, smoke completely filled store (5), approximately filled half $(1 / 2)$ of corridor (1), continued to spread in corridor (5), and started to spread in corridor (6), Fig. 13(h).

9. After 200 seconds (5 minutes), smoke completely filled store (5), approximately filled $80 \%$ of corridor (1), continued to spread in corridors (5) and (6), Fig. 13(i).

10. After 300 seconds, smoke completely filled store (5) and corridor (1), continued to spread in corridors(5) and (6), started to enter stores (4) and (6), and went outside the mall through main gates (1) and (4), Fig. 13(j).

11. After 420 seconds (7 minutes), smoke completely filled store (5) and corridor (1), continued to spread in corridors (4), (5) and (6), spread more in stores (4) and (6), and continued to move outside the mall through main gates (1) and (4), Fig. 13(k). 


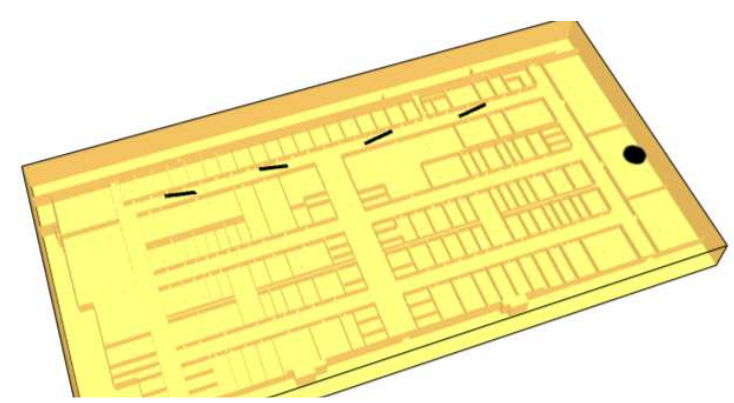

Figure 13(a). $5 \mathrm{Sec}$

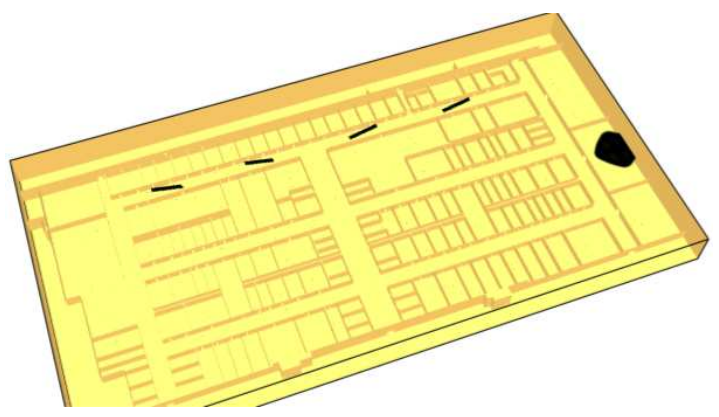

Figure 13(b). $10 \mathrm{Sec}$.

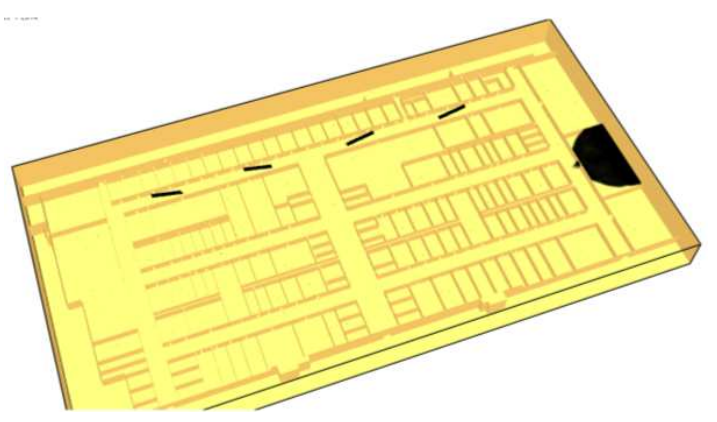

Figure 13(c). $20 \mathrm{Sec}$.

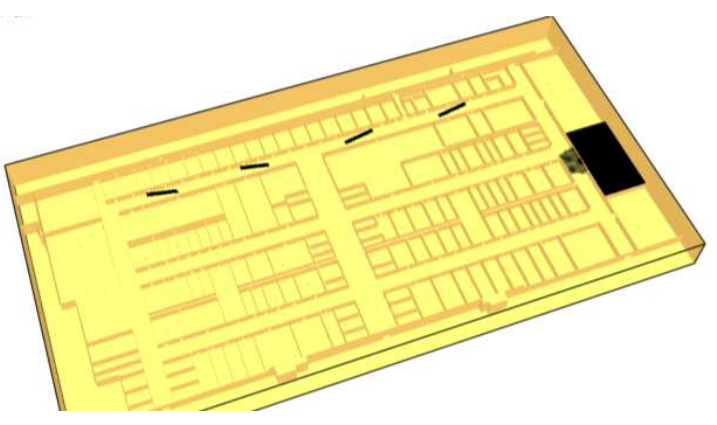

Figure 13(d). $40 \mathrm{Sec}$.

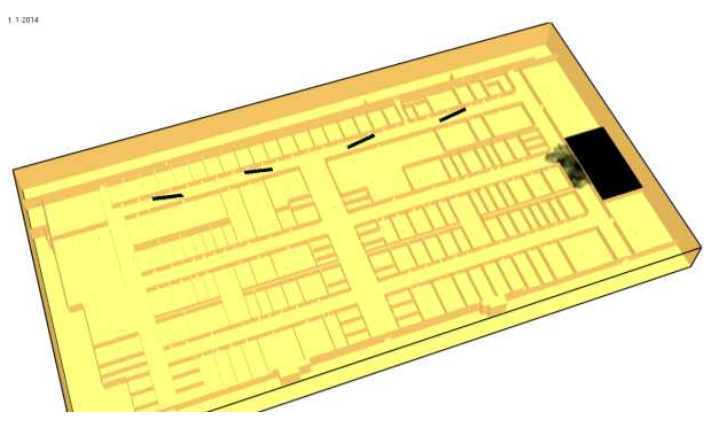

Figure 13(e). $60 \mathrm{Sec}$. (1 Min.).

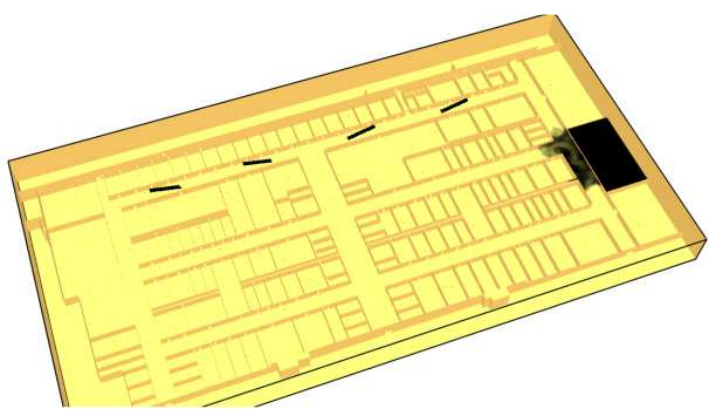

Figure 13(f). $80 \mathrm{Sec}$

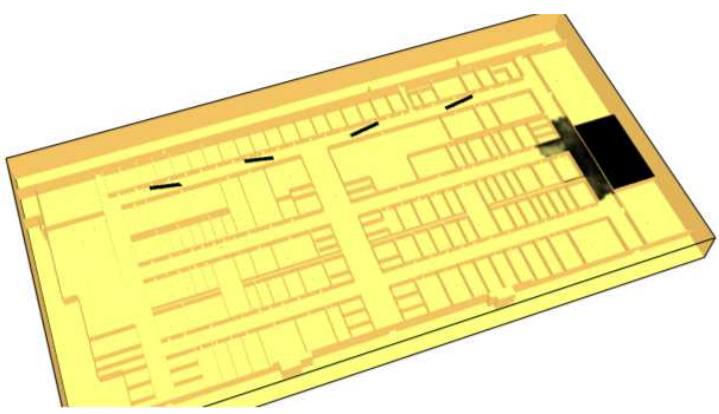

Figure 13(g). $100 \mathrm{Sec}$.

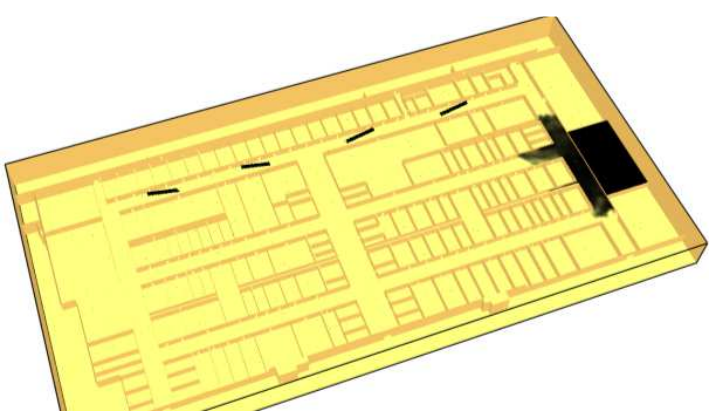

Figure 13(h). 120 Sec. (2 Min.).

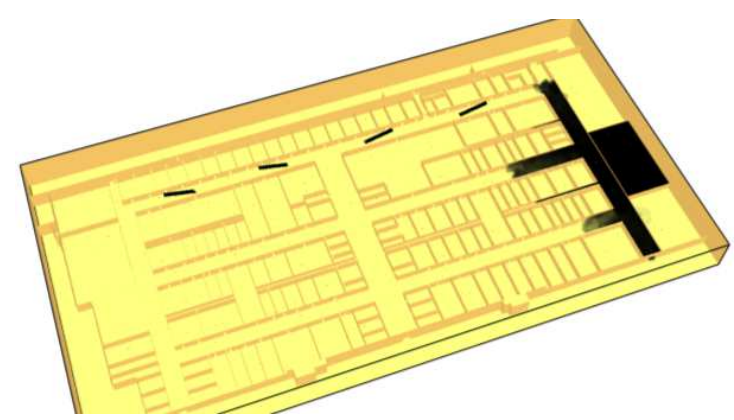

Figure 13(i). $200 \mathrm{Sec}$.

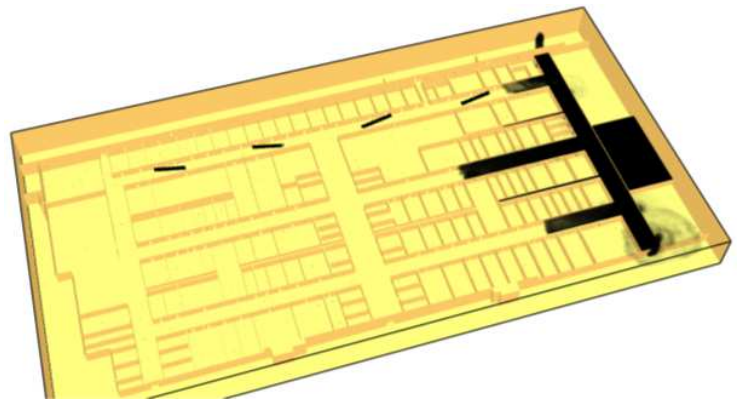

Figure 13(j). 300 Sec. (5 Min.) 


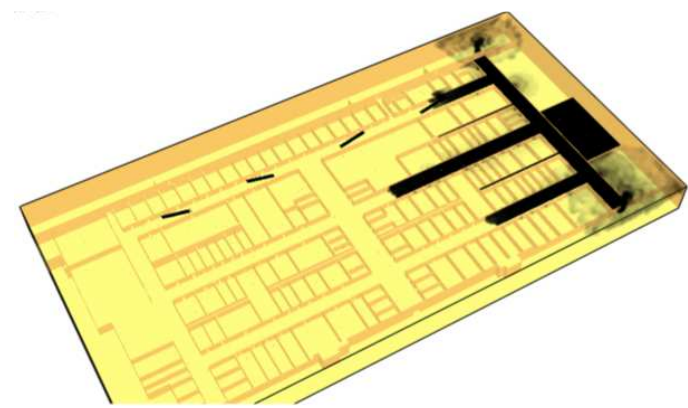

Figure 13(k). $420 \mathrm{Sec}$. (7 Min.).

Figure 13. Smoke propagation with time, Case (4).

Figure 14 shows the temperature distribution near the area of fire. Figure 14(a) shows the temperature distribution in a vertical plane passing through the fire spot and in the normal direction to the mall front. It is clear that the maximum temperature of $100^{\circ} \mathrm{C}$ is reached in the fire spot. Figure 14(b) shows the temperature distribution in another vertical plate, which is parallel to the plane of Fig. 14(a) but $10 \mathrm{~m}$ away from the fire spot. The maximum temperature is $80^{\circ} \mathrm{C}$. Figure 14(c) shows the temperature distribution in a vertical plane parallel to the mall front and $15 \mathrm{~m}$ away from the fire spot. The maximum temperature is about $50^{\circ} \mathrm{C}$. Figure $14(\mathrm{~d})$ indicates that the sprinkles in the fire region worked successfully.

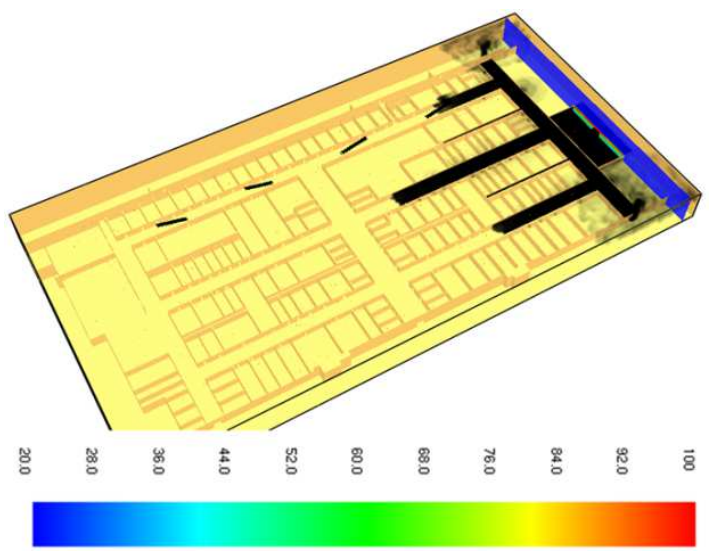

Figure 14(a). Temperature distribution in a vertical plane passing through the fire spot and in the normal direction to the mall front.

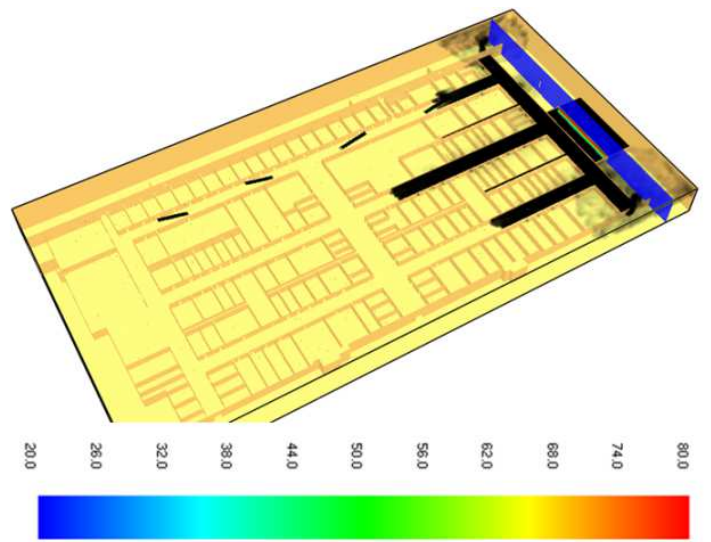

Figure 14(b). Temperature distribution in a vertical plane $10 \mathrm{~m}$ away from the fire spot and in the normal direction to the mall front.

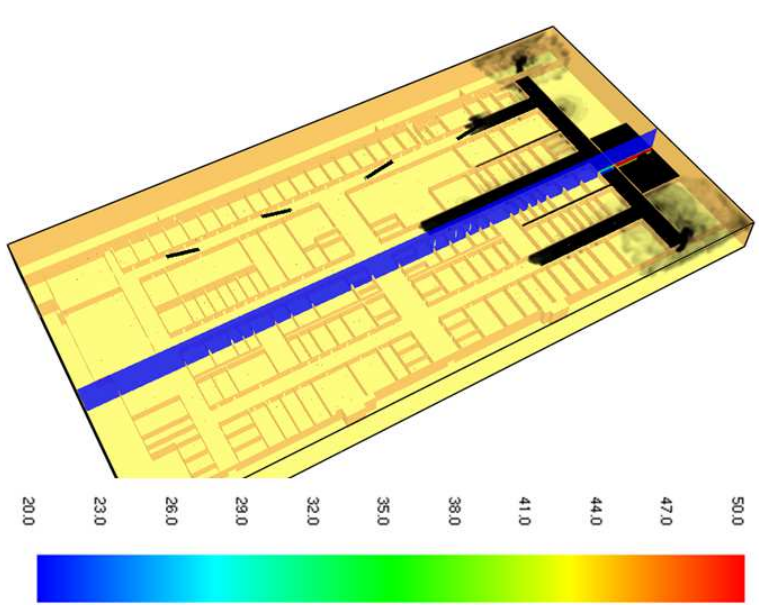

Figure 14(c). Temperature distribution in a vertical plane parallel to the mall front and $15 \mathrm{~m}$ away from the fire spot.

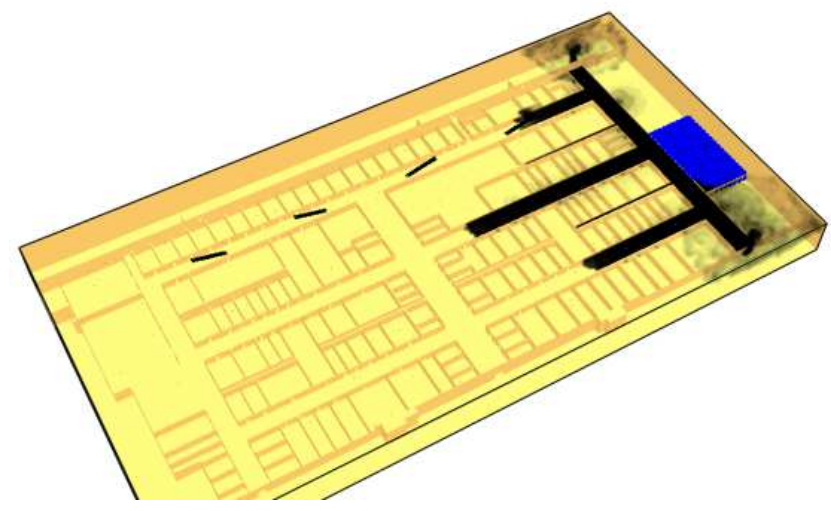

Figure 14(d). The working sprinkles in the fire region.

Figure 14. Temperature distribution near the area of fire, Case(4).

\section{Conclusions}

The present investigation concerns smoke propagation and evacuation due to fires in a large shopping center (mall) in Makkah, Saudi Arabia. The mall is a two-story building. Four fires cases were considered. Half of the cases were implemented for the ground floor and the other half were implemented for the upper floor.

Based on the present results, the following concluding points can be stated:

1- The large volume of such malls and the complexity of their structure make it very difficult to predict the smoke movement in case of fire without actual computational studies. Thus, the location of fire has a noticeable effect on the smoke propagation due to the interference of the stores, corridors, facility, etc. of the mall.

2- Smoke may spread rapidly in such malls. It also moves from one floor to another through architecture openings (after about 3 minutes in the present study).

3- As the used area of the upper floor is less than its total area, about $900 \mathrm{Sec}$. (15 Min.) were sufficient to approximately fill the occupied area of the floor with smoke. However, only about two-thirds of the ground 
floor was full with smoke after $900 \mathrm{Sec}$. (15 Min.).

4- For all the present four fire cases, the sprinkles in the fire region operated successfully. The sprinkles were not able to overcome the fire because the HRRPUA of the fire was set as constant. However, they slightly lowered the temperature in the fire region.

5- The maximum computed temperature was $105^{\circ} \mathrm{C}$ at the fire spot, which is sufficient to cause severe injuries to occupants.

\section{Nomenclature}

\begin{tabular}{|c|c|}
\hline$\dot{m}_{b}^{m}$ & $\begin{array}{l}\text { : Production rate of species by evaporating } \\
\text { droplets or particles }\end{array}$ \\
\hline $\bar{p}_{\mathrm{m}}^{\mathrm{n}}$ & : Background pressure at the $\mathrm{n}^{\text {th }}$ time step \\
\hline$\dot{q}^{\prime \prime}$ & : Conductive and radiative heat fluxes \\
\hline$\dot{q}^{\prime \prime \prime}$ & $\begin{array}{l}\text { : Heat release rate per unit volume from a } \\
\text { chemical reaction }\end{array}$ \\
\hline$\dot{q}_{b}^{\prime \prime \prime}$ & $\begin{array}{l}\text { : Energy transferred to the evaporating } \\
\text { droplets }\end{array}$ \\
\hline $\bar{u}^{\mathrm{n}}$ & : Patch-average velocity field \\
\hline$H^{n}$ & : Perturbation pressure at the $\mathrm{n}^{\text {th }}$ time step \\
\hline$Y_{\alpha}^{\mathrm{n}}$ & : Species mass fractions at the $\mathrm{n}^{\text {th }}$ time step \\
\hline$u^{\mathrm{n}}$ & : Velocity components at the $\mathrm{n}^{\text {th }}$ time step \\
\hline$u_{i-1, j k}^{n}$ & $\begin{array}{l}: \mathrm{x} \text {-component of velocity at the negative- } \\
\text { oriented face of the } \mathrm{ijk} \mathrm{k}^{\text {th }} \text { cell }\end{array}$ \\
\hline$u_{i j k}^{n}$ & $\begin{array}{l}: \mathrm{x} \text {-component of velocity at the positive- } \\
\text { oriented face of the } \mathrm{ijk}^{\text {th }} \text { cell }\end{array}$ \\
\hline $\mathrm{D}() / \mathrm{Dt}$ & : Material derivative \\
\hline$f_{b}$ & $\begin{array}{l}\text { : External forces such as the drag exerted by } \\
\text { liquid droplets }\end{array}$ \\
\hline $\mathrm{h}_{\mathrm{s}}$ & : Sensible enthalpy \\
\hline $\mathrm{i}, \mathrm{j}, \mathrm{k}$ & $\begin{array}{l}\text { : Indices representing the position of the cell } \\
\text { in the } x, y, z \text { directions, respectively }\end{array}$ \\
\hline $\mathrm{K}$ & : Thermal conductivity \\
\hline $\mathrm{P}$ & : Pressure \\
\hline $\mathrm{p}(\mathrm{x}, \mathrm{y}, \mathrm{z})$ & : Spatially resolved pressure \\
\hline $\mathrm{p}_{\mathrm{m}}(\mathrm{z}, \mathrm{t})$ & : Average or background pressure \\
\hline $\mathrm{S}_{\mathrm{ij}}$ & : Symmetric rate-of-strain tensor \\
\hline $\mathrm{T}$ & : Temperature \\
\hline $\mathrm{u}=[\mathrm{u}, \mathrm{v}, \mathrm{w}] \mathrm{T}$ & : Three components of velocity \\
\hline $\mathrm{uu}$ & : Diadic tensor \\
\hline $\mathrm{Y} \alpha$ & : Individual gaseous species \\
\hline
\end{tabular}

\section{Greek}

$\rho_{i j k}^{n} \quad$ : Density at the $\mathrm{n}^{\text {th }}$ time step in the center of the cell whose indices are $\mathrm{i}, \mathrm{j}, \mathrm{k}$

$\rho^{\mathrm{n}} \quad:$ Density at the $\mathrm{n}^{\text {th }}$ time step

$\nabla \dot{u} \quad$ : Velocity divergence

$\mu \quad$ : Dynamic viscosity

$\rho \quad$ : Density

$\tau_{\mathrm{ij}} \quad:$ Stress tensor

\section{Abbreviations}

$\begin{array}{ll}\text { 2D } & \text { : Two-dimensional } \\ \text { CFD } & \text { : Computational Fluid Dynamics } \\ \text { DNS } & \text { : Direct Numerical Simulation } \\ \text { Evac } & : \text { Evacuation software } \\ \text { FDS } & : \text { Fire Dynamics Simulator } \\ \text { HRRPUA } & : \text { Heat Release Rate Per Unit Area } \\ \text { HST } & : \text { Hot Smoke Tests } \\ \text { LES } & : \text { Large Eddy Simulation } \\ \text { NIST } & : \text { National Institute of Standards and } \\ & \text { Technology }\end{array}$

\section{References}

[1] P. Smardz, Validation of Fire Dynamics Simulator (FDS) for Forced and Natural Convection Flows, Master of Science in Fire Safety Engineering, University of Ulster, United Kingdom, October 2006.

[2] PyroSim User Manual, Thunderhead Engineering, 2014.

[3] A. M. Christensen, and D. J. Icove, "The Application of NIST's Fire Dynamics Simulator to the Investigation of Carbon Monoxide Exposure in the Deaths of Three Pittsburgh Fire Fighters", J. Forensic Sci., Jan. 2004, Vol. 49, No. 1, pp.104-107.

[4] Use FDS to Assess Effectiveness of Air Sampling Smoke Detection in Large Open Spaces, Xtralis VESDA White Paper, Doc. 16998_00.

[5] A. Webb, FDS Modelling of Hot Smoke Testing, Cinema and Airport Concourse, Worcester Polytechnic Institute, USA, M.Sc. degree in Fire Protection Engineering, November 29, 2006.

[6] S. Jianyong, and C. Longzhu, "Analysis and Assessment of Whole Structural Fire Safety for Public Buildings", ISGSR2007 First International Symposium on Geotechnical Safety \& Risk, Shanghai Tongji University, China, Oct. 18-19, 2007.

[7] A. Lönnermark, and A. Björklund, "Smoke Spread and Gas Temperatures during Fires in Retail Premises-Experiments and CFD Simulations", SP Technical Research Institute of Sweden, Fire Technology SP Report 2008:55, ISBN: 978-9186319-16-8, ISSN: 0284-5172.

[8] D. Gottuk, C. Mealy, and J. Floyd, "Smoke Transport and FDS Validation", Fire Safety Science, Vol. 9, pp. 129-140, 2008. Doi: 10.3801/IAFSS.FSS.9-129.

[9] D. Ling, and K. Kan, "Numerical Simulations on Fire and Analysis of the Spread Characteristics of Smoke in Supermarket", International Conference CESM 2011, Wuhan, China, June 18-19, 2011, pp. 7-13, doi: 10.1007/978-3-64221802-6_2.

[10] L. Wang, J. Lim, and J. G. Quintiere, "Validation of FDS Predictions on Fire-Induced Flow: A Follow-Up to Previous Study", 2011 Fire and Evacuation Modeling Technical Conference, Baltimore, Maryland, USA, Aug. 15-16, 2011.

[11] M. Tabaddor, Fire Modeling of Basement with Wood Ceiling, Underwriters Laboratories Inc., USA, December 2011. 
[12] Z.-j. Yu, O. Xu, and J.-w. Han, "The Application of FDS Used in the Cabin Fire Simulation and Human Evacuation of Civil Aviation", 2012 International Conference on Mechanical Engineering and Material Science (MEMS 2012), Nov. 2012.

[13] A. F. Abdel-Gawad, and H. A. Ghulman, "Fire Dynamics Simulation of Large Multi-story Buildings, Case Study: Umm Al-Qura University Campus", International Conference on Energy and Environment 2013 (ICEE2013), Universiti Tenaga Nasional, Putrajaya Campus, Selangor, Malaysia, 5-6 March 2013. [Institute of Physics (IOP) Conference Series: Earth and Environmental Science, Vol. 16, No. 1, 2013, doi:10.1088/1755-1315/16/1/012040].

[14] A. F.AbdelGawad, "Multidisciplinary Engineering for the Utilization of Traditional Automated Storage and Retrieval System (ASRS) for Firefighting in Warehouses", American Journal of Energy Engineering (AJEE), Special Issue: Fire, Energy and Thermal Real-life Challenges, Vol. 3, No. 4-1, , pp 1-22, July 2015. doi: 10.11648/j.ajee.s.2015030401.11.

[15] A. F. Abdel Gawad, and H. A.Ghulman,"Prediction of Smoke Propagation in a Big Multi-Story Building Using Fire Dynamics Simulator (FDS)", American Journal of Energy Engineering (AJEE), Special Issue: Fire, Energy and Thermal Real-life Challenges, Vol. 3, No. 4-1, pp. 23-41, July 2015. doi: 10.11648/j.ajee.s.2015030401.12.

[16] B. Duer, "Arson Fire Destroys Strasburg Landmark", Canton Repository, 15 October 2010.

[17] Daily mail reporter, 28 May 2012.

[18] S. Malik,"17 Killed in Kolkata Market Fire", NDTV,27 February 2013.

[19] gazettenet.com, October 27, 2013.

[20] A. Raja, CNN, December 30, 2014.

[21] A. Attrino and S. Epstein, NJ Advance Media for NJ.com, February 26, 2015.
[22] BBC news, 12 March 2015.

[23] K. McGrattan, S. Hostikka, J. Floyd, H. Baum, R. Rehm, W. Mell, and R. McDermott, Fire Dynamics Simulator (Version 5), Technical Reference Guide, Volume 1: Mathematical Model, National Institute of Standards and Technology, NIST Special Publication 1018-5, 2010.

[24] Standard for the Installation of Sprinkler Systems, National Fire Protection Association (NFPA), 2013 Edition, ISBN: 978145590455-6.

[25] Standard for the Installation of Sprinkler Systems in One- and Two-Family Dwellings and Manufactured Homes, National Fire Protection Association (NFPA), 2013 Edition, ISBN: 978145590456-3

[26] Standard for the Installation of Sprinkler Systems in Low-Rise Residential Occupancies, National Fire Protection Association (NFPA), 2013 Edition, ISBN: 978-145590457-0.

[27] Recommended Practice for Fire Department Operations in Properties Protected by Sprinkler and Standpipe Systems, National Fire Protection Association (NFPA), 2010 Edition, ISBN: 978-087765967-9.

[28] National Fire Alarm and Signaling Code, National Fire Protection Association (NFPA), 2013 Edition, ISBN: 978145590464-8.

[29] L. Staffansson, Selecting Design Fires, Department of Fire Safety Engineering and Systems Safety, Lund University, Sweden, Report 7032, 2010, ISSN: 1402-3504.

[30] J. Hietaniemi, and E. Mikkola, Design Fires for Fire Safety Engineering, VTT Working Papers 139, VTT Technical Research Centre of Finland, 2010, ISBN 978-951-38-7479-7.

[31] Z.-C. Grigoraş, and D. Diaconu-Şotropa, "Establishing the Design Fire Parameters for Buildings", Bul. Inst. Polit. Iaşi, t. LIX (LXIII), f. 5, pp. 133-141, 2013. 